

\section{Sound in nature}

a model for good workspaces

For thousands of years a human being's sense of hearing has been developed and optimised for an outdoor environment, free from unnatural sound reflexes. As evolution brought us further away from the outdoors, sounds like rippling streams, birdsong and voices were replaced with unnatural sound reflexes and sounds e.g. machines and installations; Such as air conditioning, printers and phones.

This unnatural sound environment does not only disturb our hearing and communication, but also has an impact on our wellbeing and level of performance.

Today, almost $90 \%$ of our time is spent indoors, either in the office or travelling to and from our workplace. Think about it - how many hours do you spend indoors on a normal day? How do you perceive the acoustic environment in a peaceful outdoor place compared to the office?

In order to improve the indoor acoustic environment we should strive to resemble the natural outdoor acoustic environment.

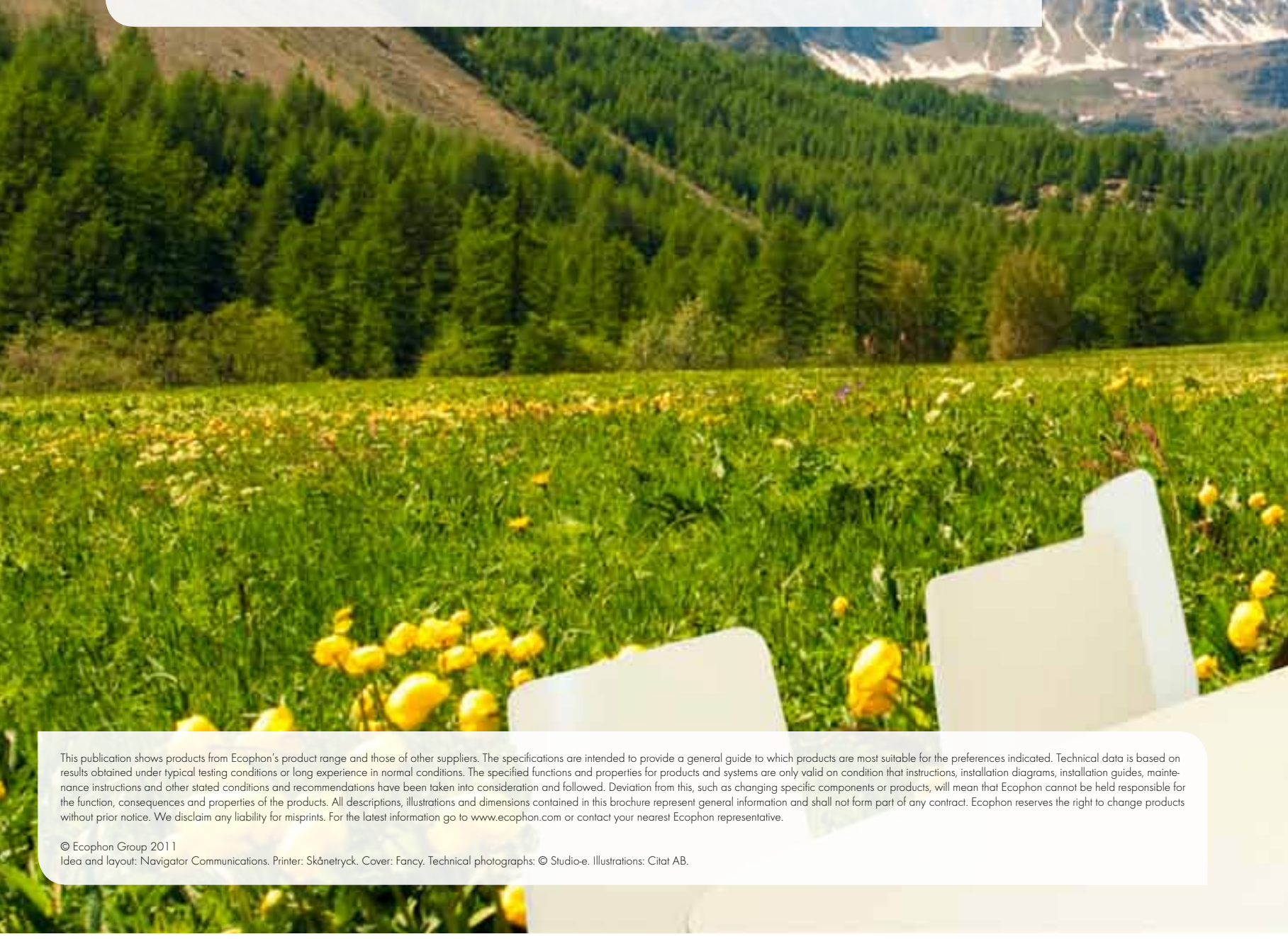




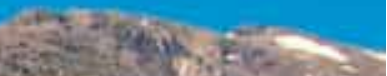

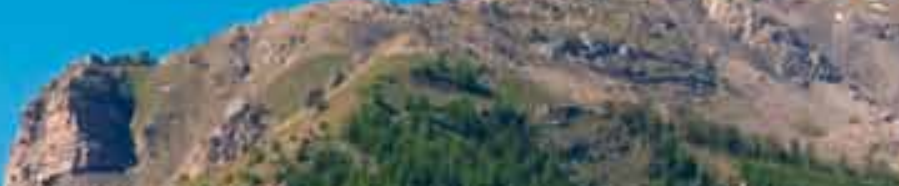

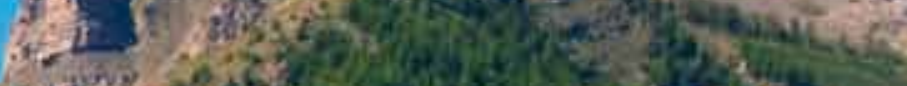

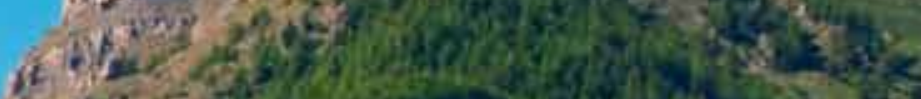

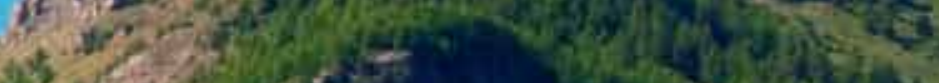

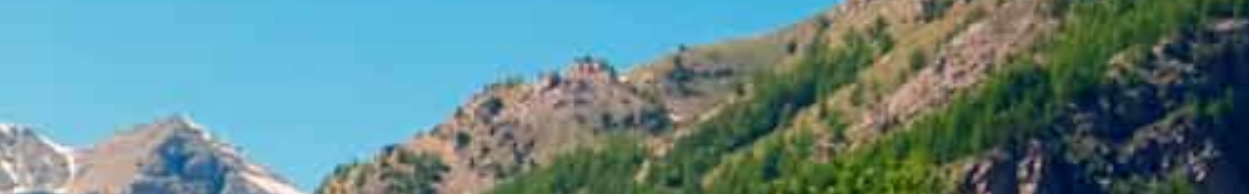

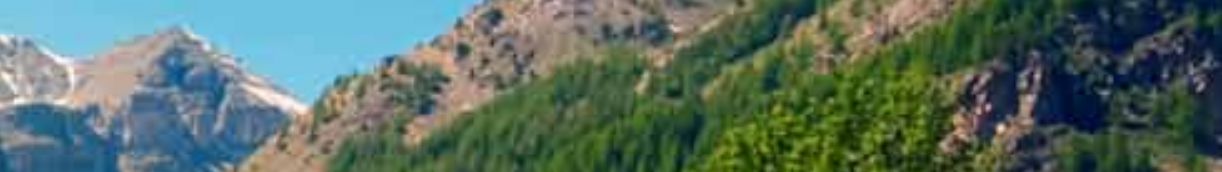

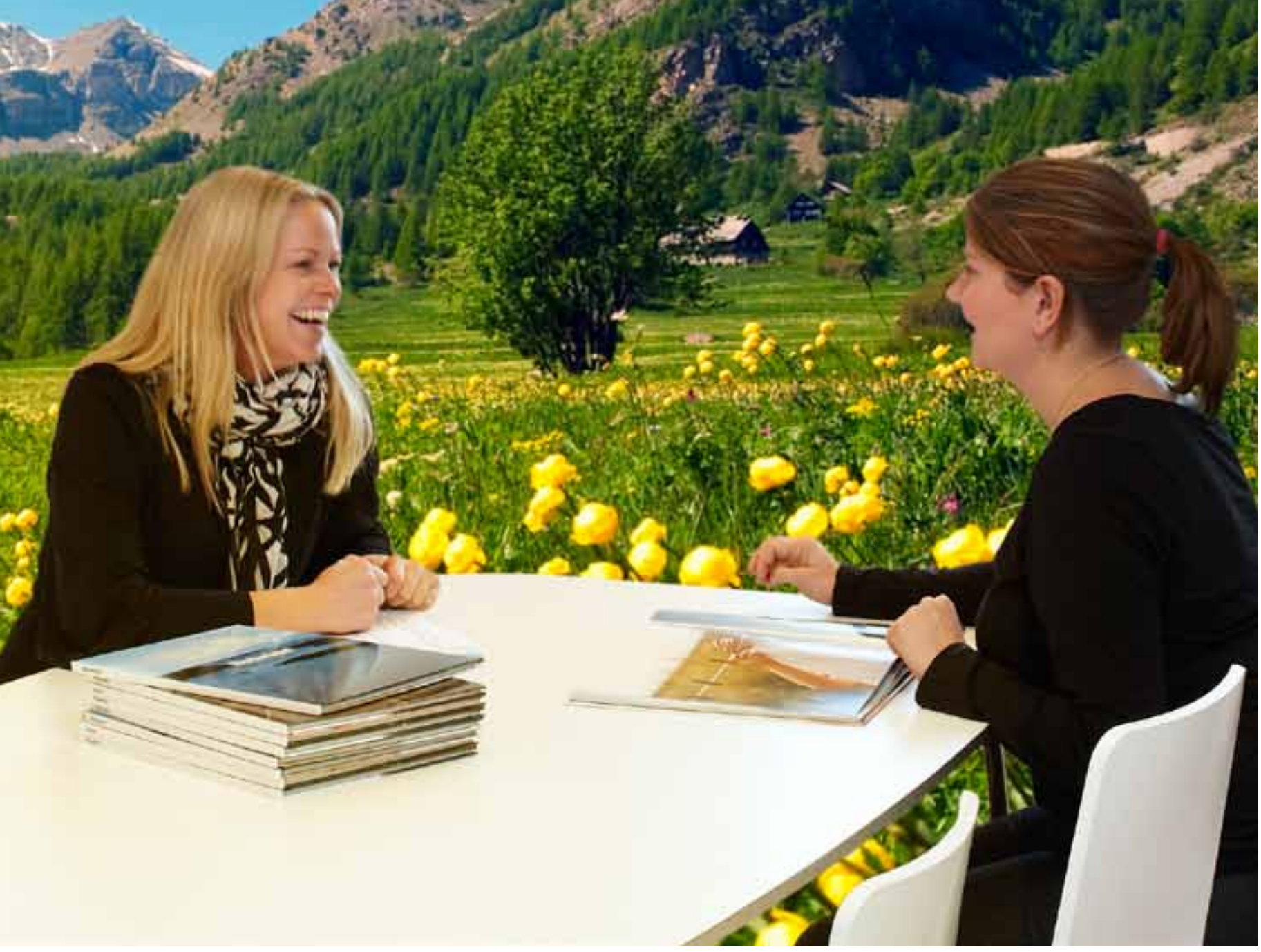




\section{Sound in the office}

\section{and how it affects us}

For people to be creative and perform to their highest standard, a good sound environment is crucial. Several studies show that the office workers main concerns are to do with sound*.

A great working environment minimises unwanted sounds such as people, phones, office equipment and ventilation, but supports sounds that contain information. Every time a person gets interrupted, the brain needs longer than expected to get back on track again, especially when performing activities that require a high amount of creative thinking*. The more complex the task, the more important it is to be able to work in peace. Unwanted sounds can also increase the feeling of stress, and can lower the motivation. To provide a good sound environment is one of the most rewarding investments a company can do.

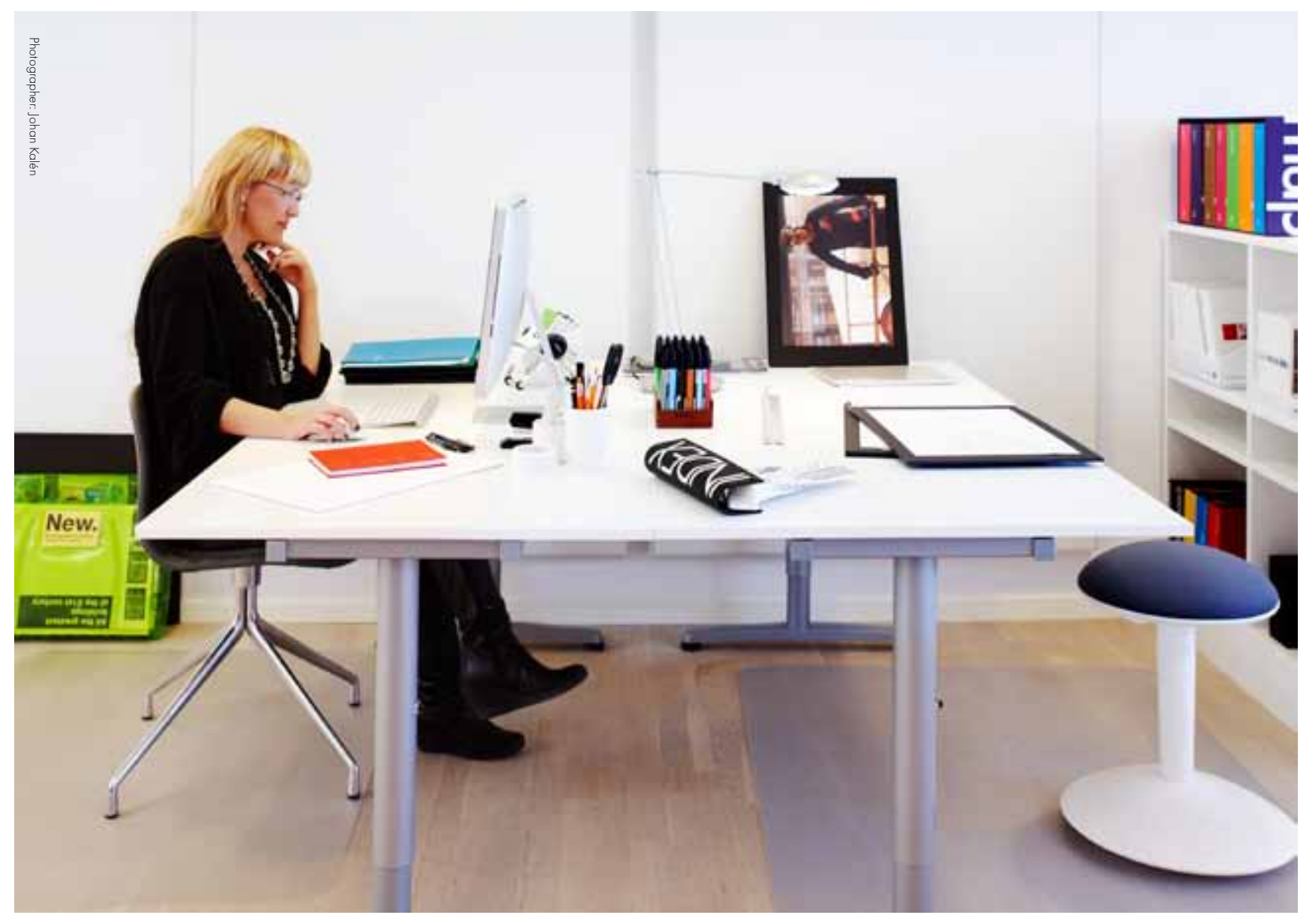




\section{The evolution of the modern office}

Working in an office is not the same as it was a few decades ago. From being a place that mainly provided the equipment needed for doing the work, an office is today a place for interaction and knowledge transfer - we meet and talk, we learn and socialise, and we find solutions together. We move towards more open and communicative office design to support interaction and collaboration between people.

\section{Organisational and behavioural development}

Office buildings today need to be flexible and must be able to be quickly adapted to organisational changes. Many companies choose to create non-territorial spaces, meaning that workers no longer have their own workspace, but can select any workspace that is free. This provides the opportunity to sit close to the people you are working with at the moment, or to select a quiet space if you need to do focused work. In the office we are affected by unnatural sound sources like ventilation, office machines, etc. However when we ask people what it is that disturbs them most we get the same answer. People are disturbed by speech that does not contain valuable information, often from long distances, and people appreciate good speech clarity within their working groups, and here lies the acoustic challenge to support sound that contains information and reduce sound that is disturbing i.e. noise.

\section{Technical construction development}

As the degree of transparency increases in modern offices, so does the amount of hard materials such as glass. Hard even surfaces reflect sound in an unnatural way which will contribute to sound propagation and increased sound level.

To improve the energy efficiency, new technologies have emerged in the building process.For example; in many cases cooling systems are installed in the soffit, these thermally active building systems (TABS), can cool down the office premises without the need for air conditioning, and are thus very energy efficient. To make this work it is not possible to use wall-to-wall acoustic ceilings, which creates the need for new innovative acoustic solutions providing a good sound environment in these types of buildings.

\section{Sound Design}

To find solutions to the acoustic challenges in the modern office, many aspects affecting the sound environment have to be taken into account. It starts with understanding how people are affected by sound, their acoustic preferences and the type of activity the room is used for, before we make the architectural design and select building materials. This holistic view for creating a good sound environment, is the foundation of Ecophon's approach to sound design. 


\section{The Ecophon approach \\ to sound design}

Flexible workspaces and open plan solutions are increasingly common in office buildings. The idea is to facilitate communication while increasing flexibility and efficiency. However, this new openness is sometimes achieved at the expense of the acoustic environment. Ecophon has spent many years developing know-how, our holistic approach, and system solutions to create an optimal sound environment in open-plan offices.

\section{Meeting the standards}

Research in the field points to the fact that in open plan solutions, it is how far the sound travels that influences how people experience the sound environment. It is therefore important to focus on limiting the sound propagation in space (also called spatial decay). Measurement procedures of spatial decay and other relevant acoustic qualities in open plan spaces are planned to be included in the upcoming ISO-standard*. These acoustic qualities can be converted into a "radius of acoustic comfort" (distraction distance) in open plan offices, a value which can be incorporated into office design.

* Final draft committee standard: ISO/FDIS 3382-3: Measurement of room acoustic parameters - Part 3: Open plan offices

\section{The radius of acoustical comfort}

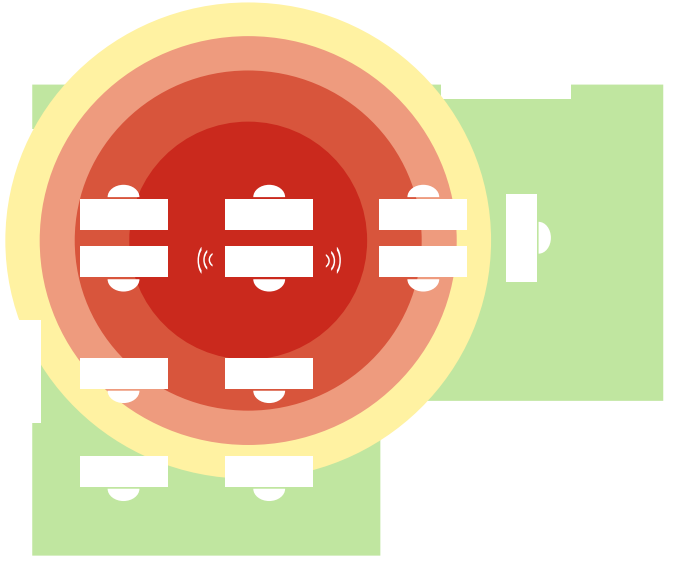

Without acoustic systems the sound from a worker will propagate and cause disturbance to other people in the room.

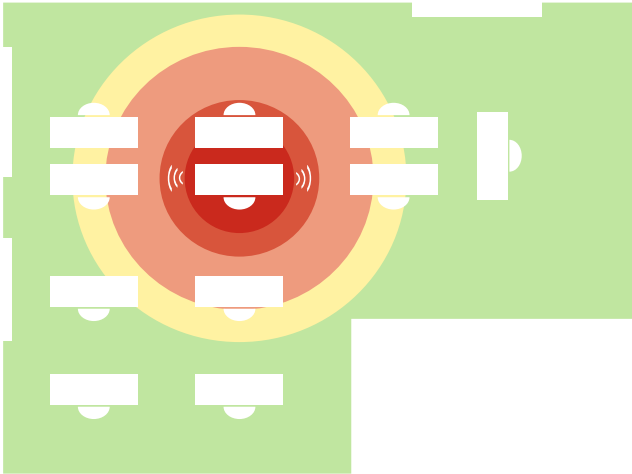

When the sound propagation is limited by acoustic systems, the workers experience a much better sound environment. 


\section{Going beyond the standards}

When aiming to define people's acoustic preferences, describe, or assess the acoustic environment; it is advisable to use acoustic parameters that reflect the relevant acoustic demands and preferences. Most acoustic standards around the world include requirements regarding reverberation, but people often have other acoustic preferences that go beyond reverberation. Moreover, our sense of hearing is multi dimensional, so it cannot be defined by a single parameter.

At Ecophon, our approach is to take the human perception into account and to work with at least four acoustic qualities, which allows for a more accurate description of the acoustic environment.

\section{Find out how the people perceive and are affected by sound}

Start by asking people how they perceive the acoustic environment and what their acoustic preferences are.

\section{Take activities into account}

Different activities require different acoustic priorities. Find out what the room is to be used for and the most highly prioritised acoustic parameters, such as sound strength, sound propagation, speech clarity or reverberation.

\section{Use relevant acoustic parameters}

Acoustic perception is multi-dimensional, so several acoustic parameters are needed to objectively define acoustic requirements and ascertain that they are fulfilled.

- If the main acoustic priority is lowering the sound strength, $G(\mathrm{~dB})$ is a relevant acoustic measure.

- If the main acoustic priority is reducing sound propagation, DL2 (dB) and DLf (dB) are relevant acoustic measures.

- If the main acoustic priority is optimal speech clarity, D50 (\%) is a relevant acoustic measure.

- If the main acoustic priority is optimal reverberance, reverberation time $T$ (sec) is a relevant acoustic measure.

\section{Design the room and choose materials that enhance acoustic comfort}

When designing the room, it is important to consider how the room's shape, volume and choice of materials will affect the acoustics.

\section{The four acoustic qualities *}

Sound strength - $G(d B)$ measures the extent to which a room amplifies the sound from a sound source, compared to measurement in a laboratory with no sound reflections.

Sound propagation - $\mathrm{DL} / \mathrm{dB})$ measures how the room contributes to sound propagation compared to an outdoor environment with no sound reflections, at a specified distance from the sound source. $\mathrm{DL}_{2}(\mathrm{~dB})$ measures the extent to which the sound strength drops when the distance from the sound source is doubled.

Speech clarity $-D_{50}(\%)$ is the energy of all useful reflections including the direct sound, which enhance speech clarity, divided by the total energy including the direct sound. The higher the value, the better the speech clarity.

Reverberation - Reverberation time, $T$ (sec) indicates how long it takes for the sound to drop by $60 \mathrm{~dB}$ after a sound source stops emitting sound.

*) According to ISO 14257, ISO 3382-1, ISO 3382-2.. 


\section{Benefits}

\section{of a good sound environment}

Having a good sound environment is integral to providing people with a sense of well-being and satisfaction about the office in which they work every day. A good working environment supports people in both communication and concentration. The result will be better wellbeing and performance, being not only beneficial for the employees, but which increases the efficiency and productivity of the company as a whole. It will also improve the company's popularity as a

What happens to people in a good sound environment?*

- Increased well-being, less tiredness

- Increased job satisfaction

- Easier to concentrate

- Easier to communicate

- Less secretion of stress hormones

- More attempts at solving difficult tasks

- More ergonomic postural changes

- Fewer errors, increased accuracy workplace, which in turn can help you attract highly qualified employees.

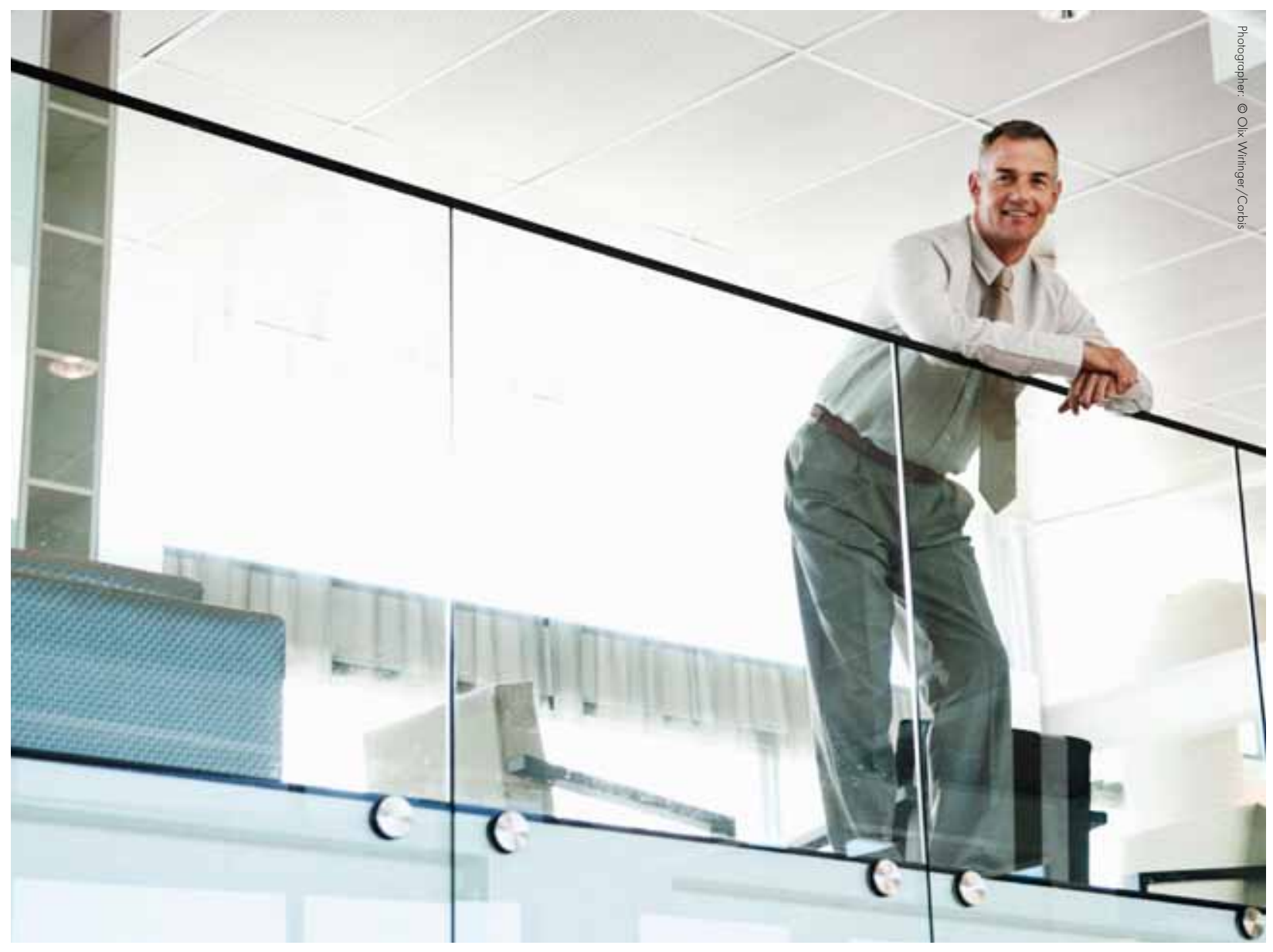




\section{Different office activities}

\section{have different acoustic needs}

A modern office includes many different spaces. When planning an office space, it is necessary to take a comprehensive view and consider all aspects that affect the sound environment (the people, the room and the activities). The challenge lies in making the indoor acoustic environment as similar as possible to an outdoor environment, since we feel most comfortable, acoustically, outdoors.

In terms of practical planning, it is vital to set realistic goals, all disturbing noise cannot always be eliminated, but the acoustic benefits should outweigh the drawbacks. Instead of asking ourselves what we don't want, we should pinpoint what we do want.

\section{Find examples of typical office spaces on the following pages:}

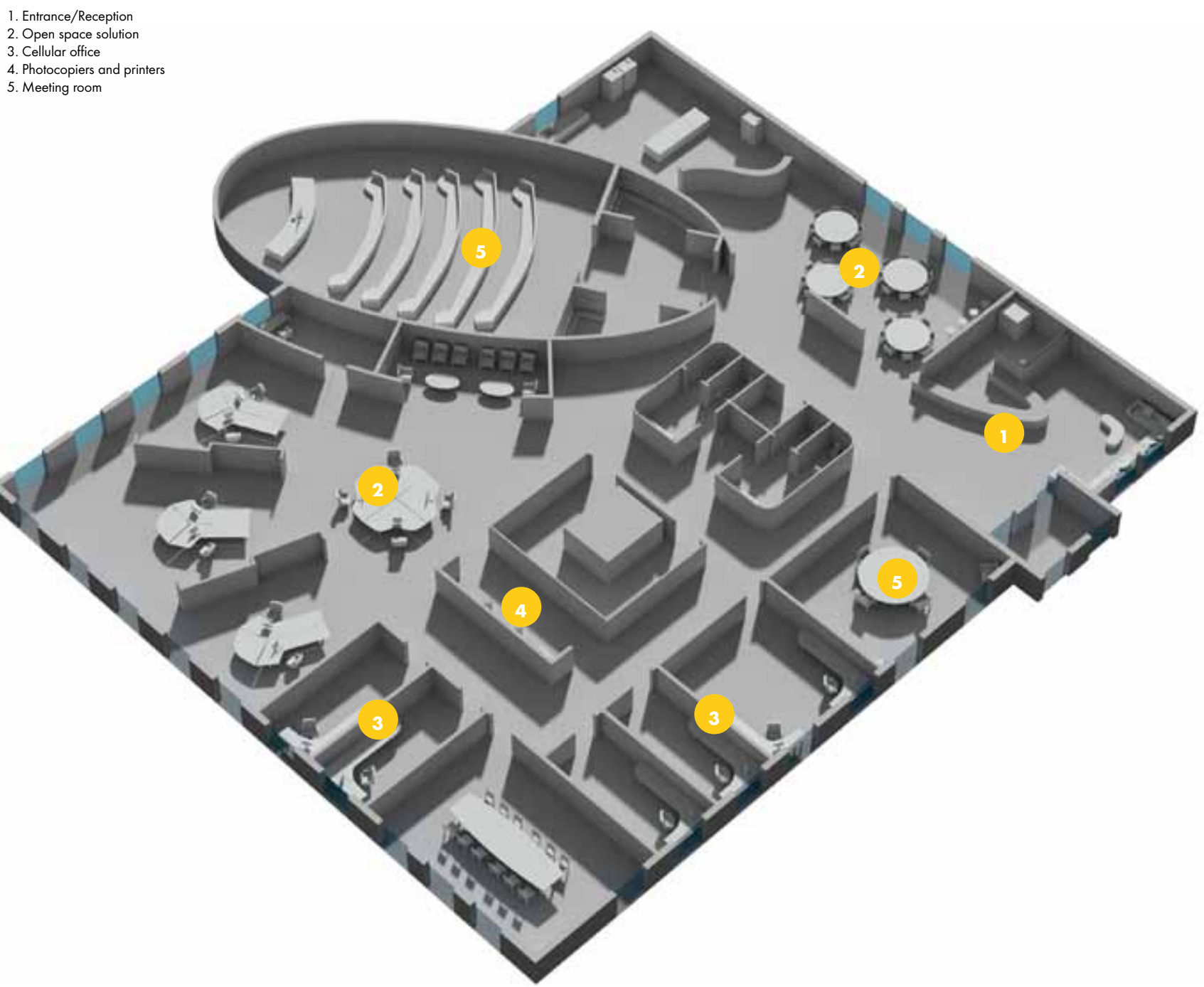




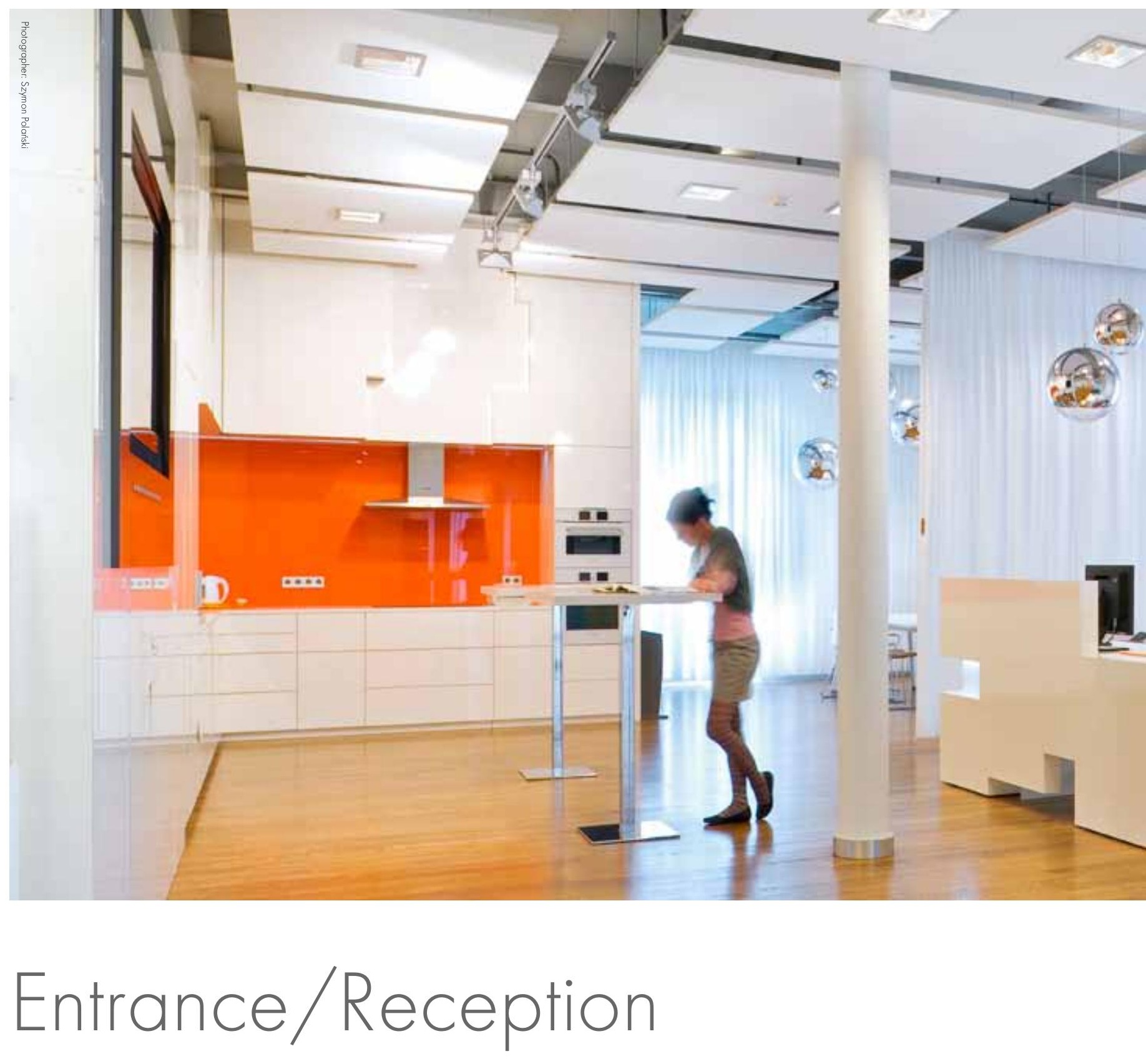

The entrance and reception area represents the company to the outside world and gives visitors their first impression. When designing the reception, a balance must be achieved between attaining short-range speech clarity and minimising longer-range sound propagation.

\section{The room}

Entrances often have hard surfaces to withstand wear and tear. To meet acoustic requirements for low sound levels and good speech clarity, highly absorbent ceilings are required, preferably supplemented with soundabsorbing wall panels. This creates a good acoustic environment for both visitors and staff.

\section{Acoustic preferences}

Visitors and staff must be able to speak clearly without being disturbed by surrounding noises. Personal conversations and phone calls ideally should not be audible from the entrance. 

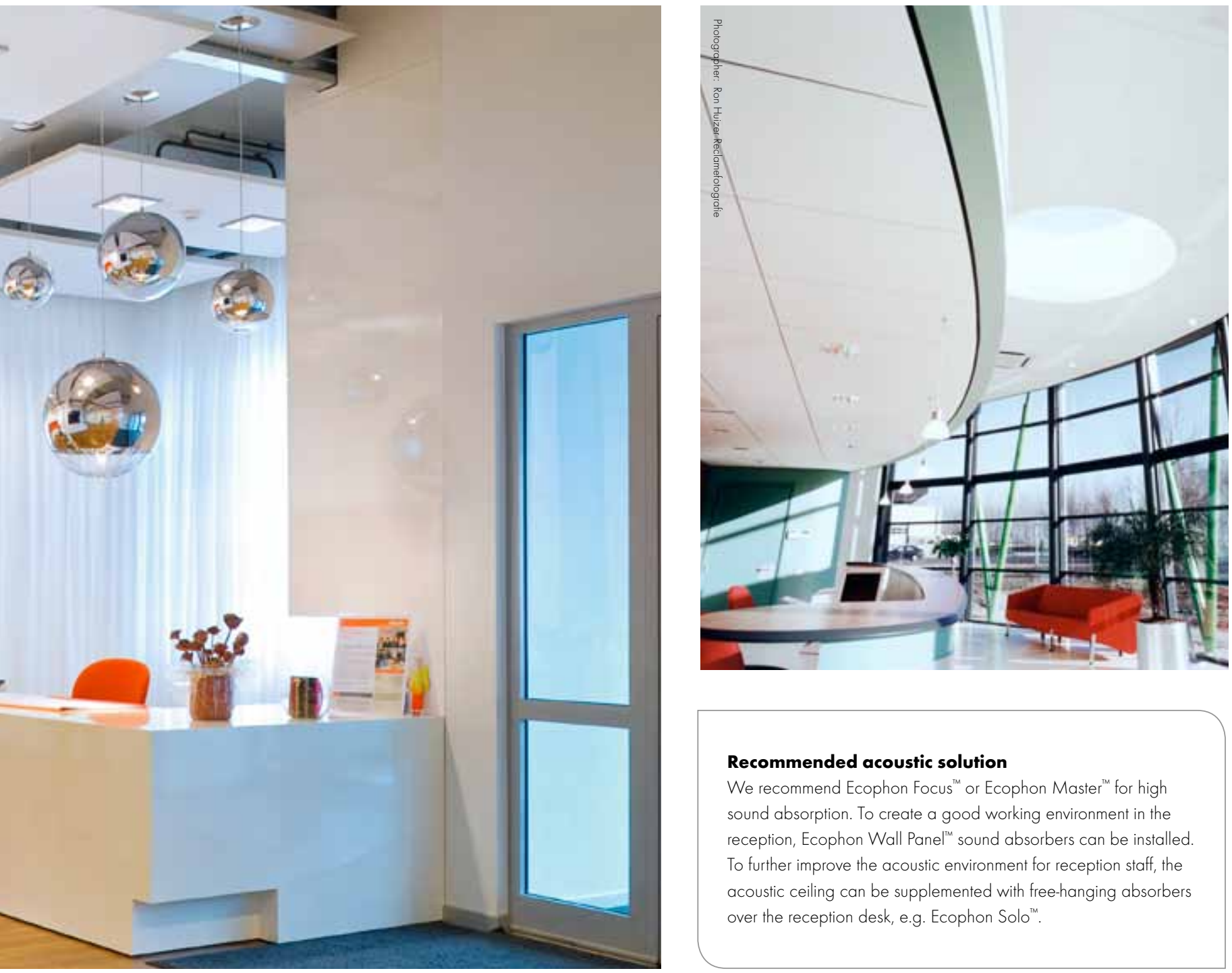

\section{Recommended acoustic solution}

We recommend Ecophon Focus ${ }^{\text {TM }}$ or Ecophon Master ${ }^{\text {tm }}$ for high sound absorption. To create a good working environment in the reception, Ecophon Wall Panel ${ }^{\text {Im }}$ sound absorbers can be installed. To further improve the acoustic environment for reception staff, the acoustic ceiling can be supplemented with free-hanging absorbers over the reception desk, e.g. Ecophon Solo ${ }^{\text {tm }}$.

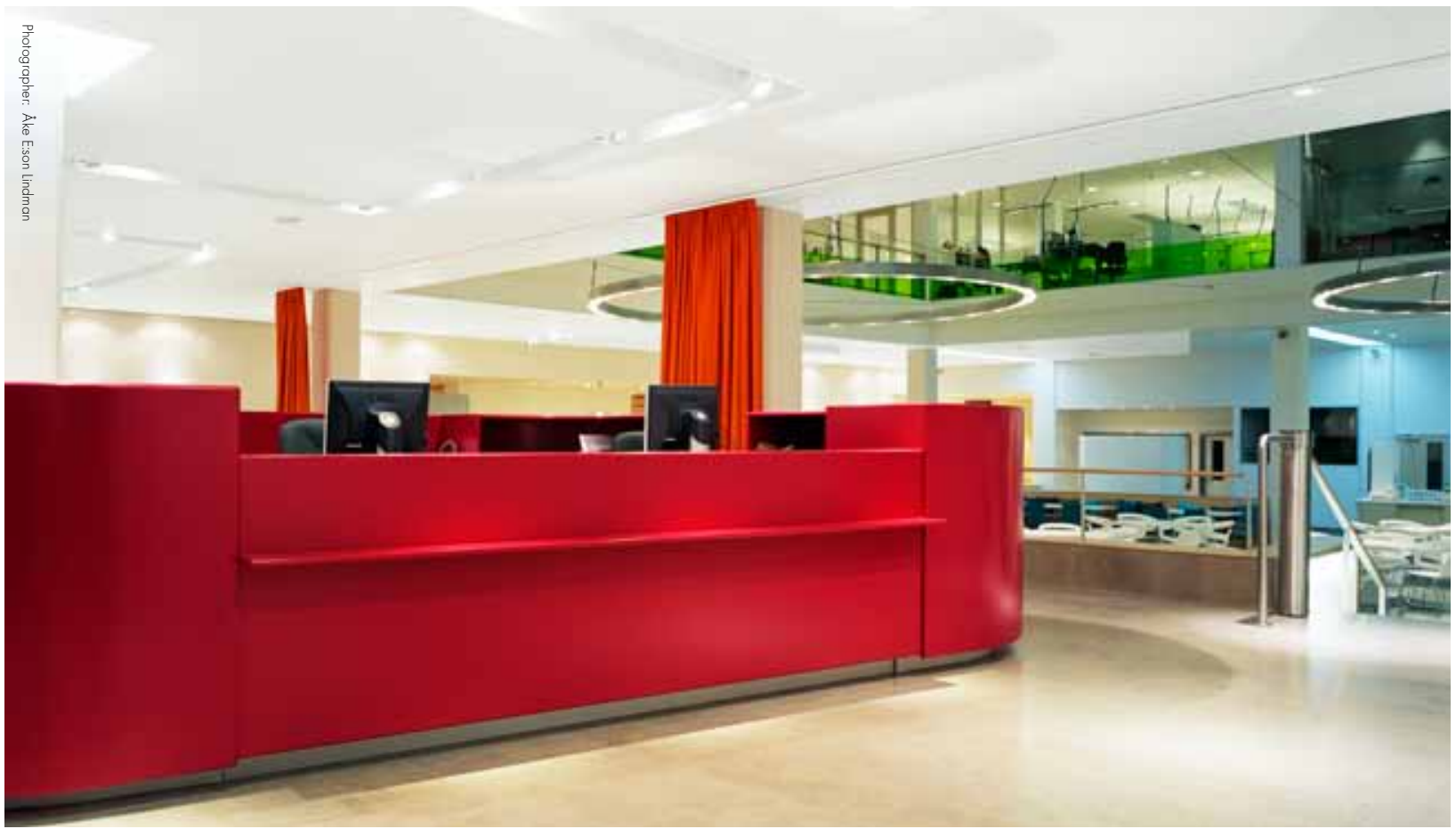




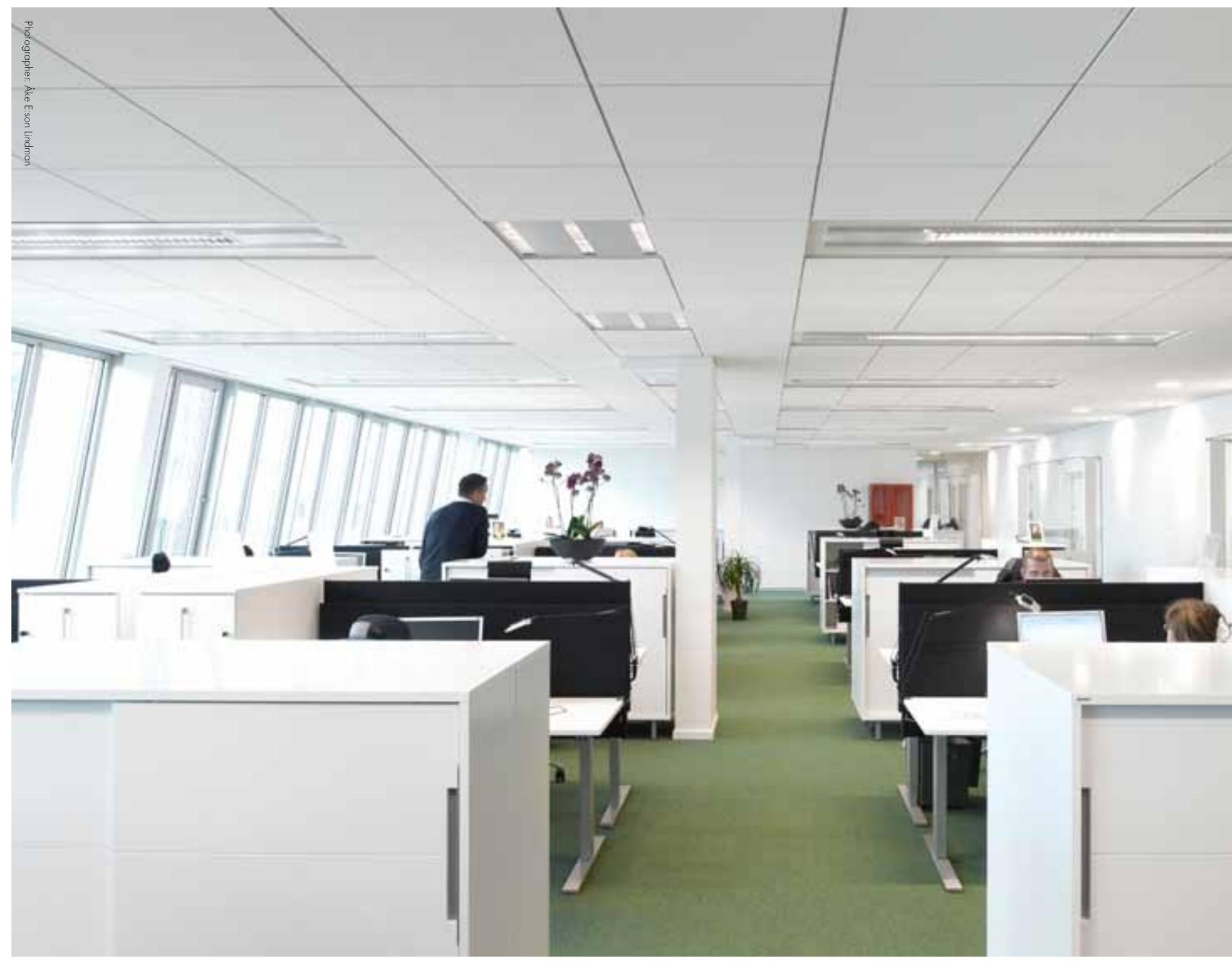

\section{Open plan solution}

Open plan solutions are frequently adopted to create flexible buildings that are quickly adapted to the companies' changing needs. An open plan solution has the advantages of facilitating interpersonal communication and knowledge transfer while allowing different groups of staff to create their own workspaces in the office. However, a disadvantage is that different work groups can disturb each other. The challenge lies in creating a sound environment that favours communication between the members of a workgroup while preventing their conversations from disturbing colleagues further away. What one person perceives as important information may be nothing but disturbing noise to someone else.

\section{The room}

An open plan area often has large windows to allow plenty of light into the space and sound reflecting glass partitions for transparency. These factors, combined with the lack of walls, make the sound travel further. To limit sound propagation, furnishing and screens must be sound-absorbing, the right size and appropriately positioned. A flexible solution that combines soundabsorbing and insulating ceiling installations, improves and promotes organisational flexibility. Also bear in mind that in an open plan office environment, it is important to have approximately one quiet room per ten employees for concentration-intensive work. 

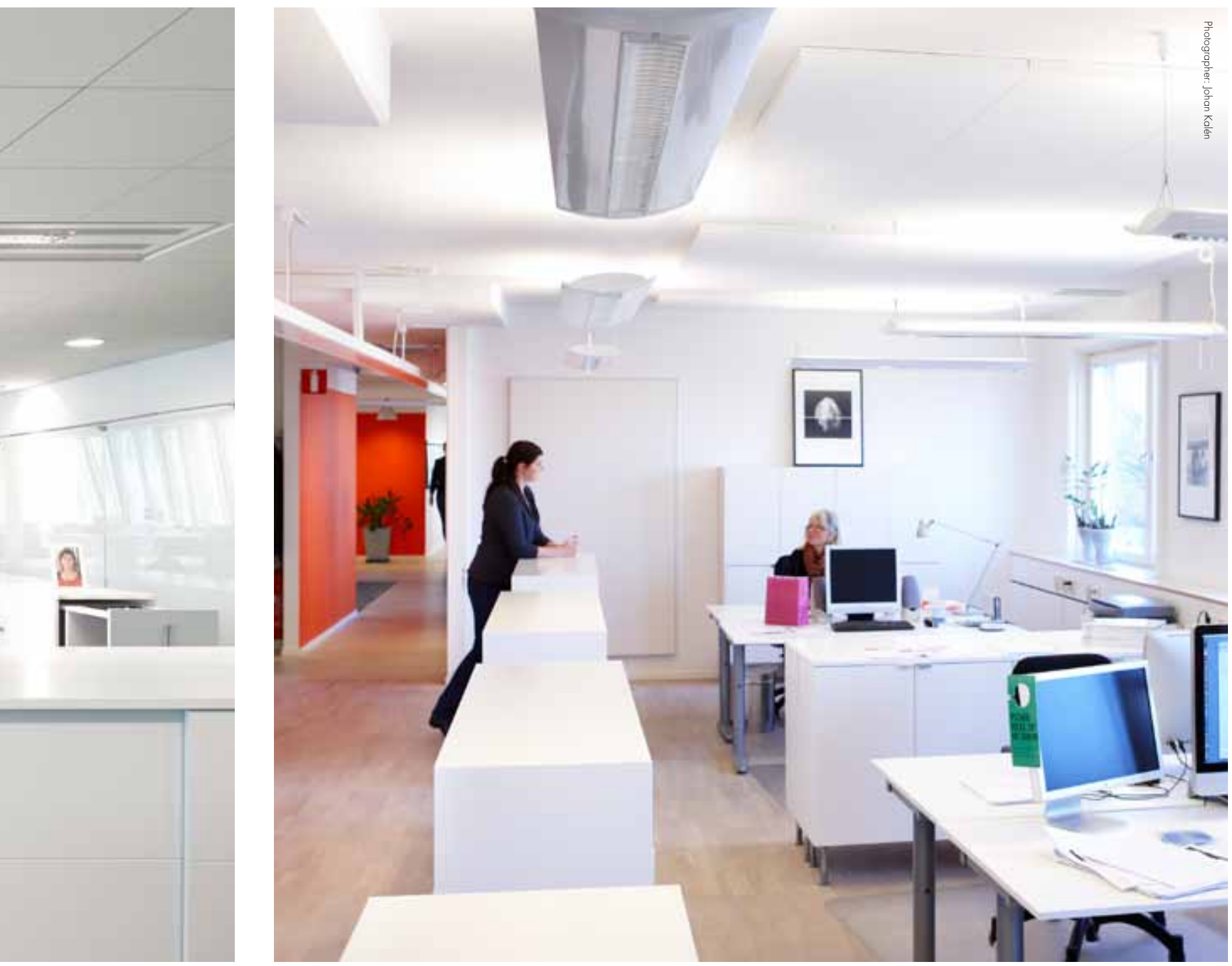

\section{Acoustic preferences}

To prevent conversations from travelling across the room, it is necessary to reduce sound propagation. This is done by installing an acoustic ceiling that limits the sound propagation efficiently (with a high AC value) supplemented with sound-absorbing office screens. During a working day, people sometimes need a quiet space where they can work undisturbed, or to go to in order not to disturb others. Quiet rooms can be created using partition walls which do not meet the soffit and are fixed flush or hard to the acoustic ceiling. To achieve adequate soundproofing, the acoustic ceilings must be both sound-absorbing and provide acoustic insulation.

\section{Recommended acoustic solution}

If the solution includes flexible modular spaces, we recommend Ecophon Combison ${ }^{\text {tm }}$ Duo for limiting sound propagation and improve sound insulation (high $\mathrm{AC}$ value and high insulation value $D_{n, f, w}$. This helps to optimise the sound environment while making it possible to build rooms with partition walls fixed, flush or hard to the acoustic ceiling. If partition walls are not needed for building rooms, we recommend Ecophon Master ${ }^{\text {rm }}$ - to minimise sound propagation efficiently (high AC value). To further reduce sound propagation and improve speech clarity in selected areas, free-hanging absorbers can be installed, such as Ecophon Solo ${ }^{\text {tm }}$ and/or Ecophon Solo ${ }^{\text {TM }}$ Baffle. 


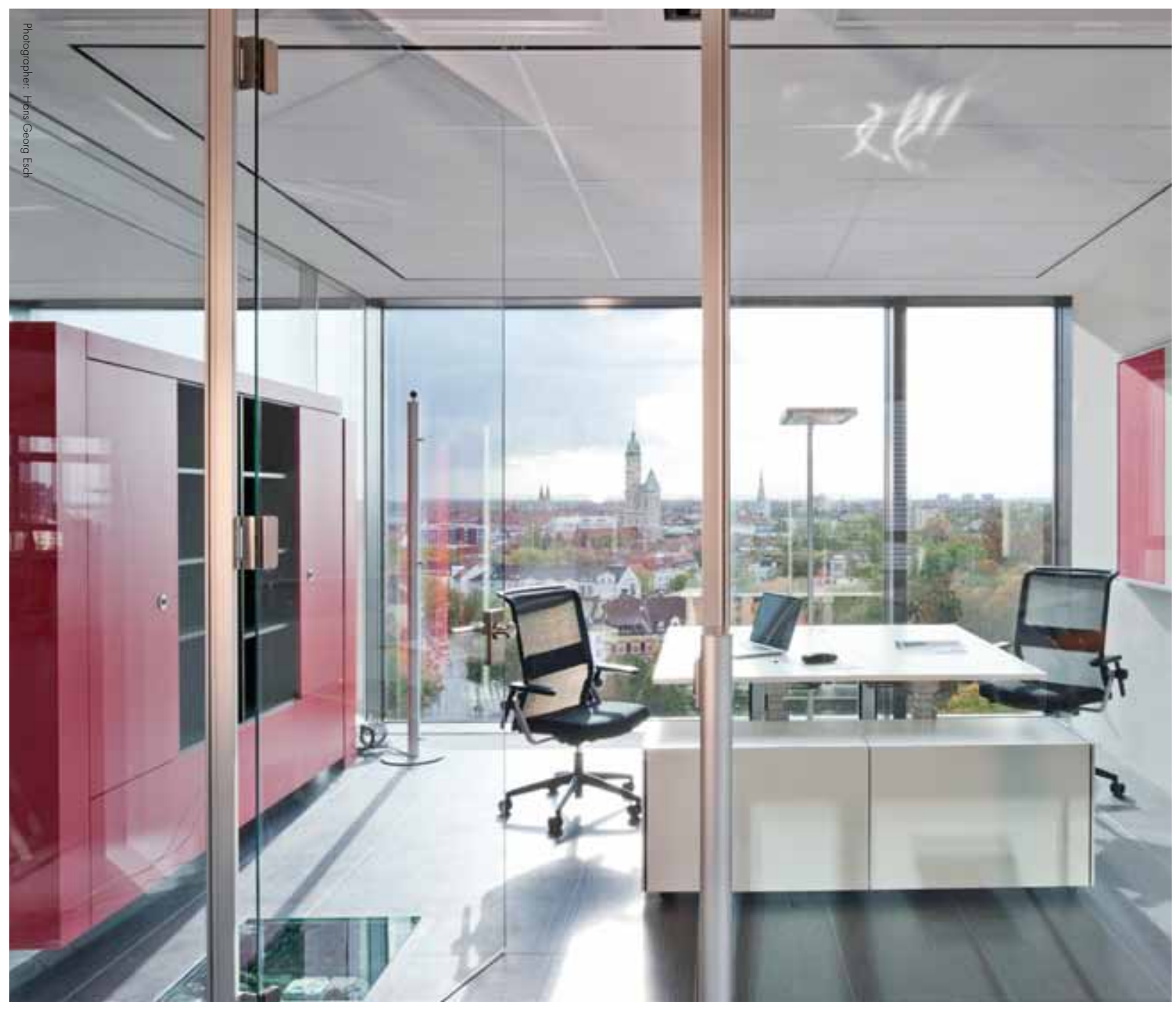

\section{Cellular office}

Cellular offices are a well-proven solution where each employee has their own room. A cellular office makes it easier to perform concentration-intensive work, but reduces opportunities for free communication and spontaneous interaction.

\section{The room}

Parallel walls can sometimes cause sound reflections between the walls, and give rise to a phenomenon known as flutter echo. This can be prevented by installing a wall absorber at ear height.

\section{Acoustic preferences}

To facilitate concentration-intensive work, the room needs to be acoustically insulated from other rooms and the corridor. To create a comfortable acoustic environment, we recommend installing high-performing sound absorbers in the ceiling.

\section{Recommended acoustic solution}

We recommend Ecophon Focus ${ }^{\text {TM }}$ for good sound absorption and flexibility when integrated ceiling installations are used. The Ecophon Wall Panel ${ }^{\text {rm }}$ is recommended to prevent horizontal sound reflections. 


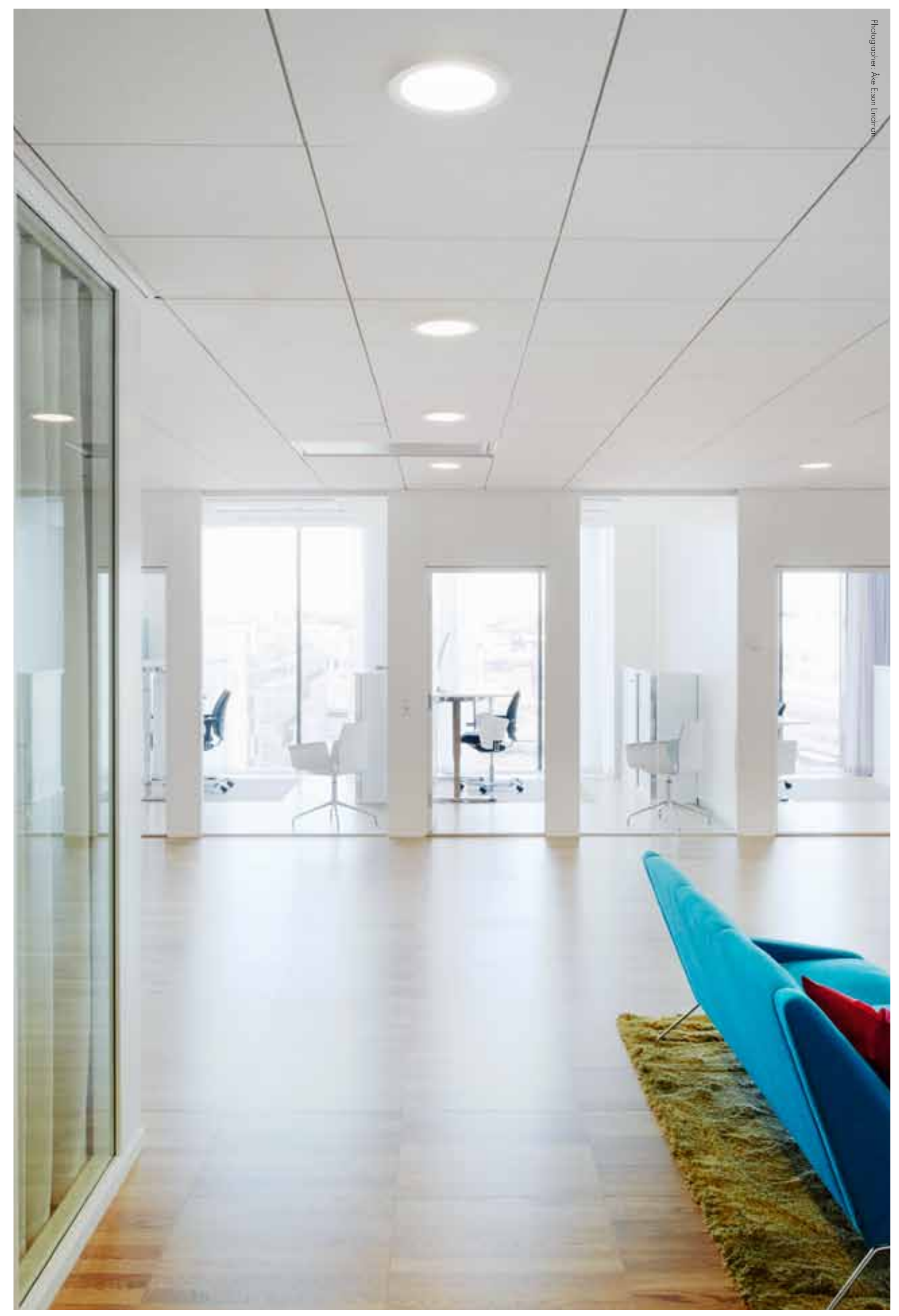




\section{Photocopiers and printers}

The equipment located in these areas are sources of noise that are almost always perceived as disturbing. The sound source should be insulated as much as possible to prevent the noise from spreading to people's workstations.

\section{The rooms}

To meet acoustic preferences for low sound level and short sound propagation, it is necessary to install high sound-absorbing ceilings and wall panels. If screens are used, they should be as sound-absorbing as possible.

\section{Acoustic preferences}

Because the noise from photocopiers and printers is usually perceived as disturbing, it should be dampened as much as possible. This is done by minimising the sound strength and sound propagation.

\section{Recommended acoustic solution}

Ecophon Master ${ }^{\mathrm{TM}}$ and Ecophon Wall Panel ${ }^{\text {IMM }}$ are recommended for optimal sound absorption, to reduce the level of sound from machines.

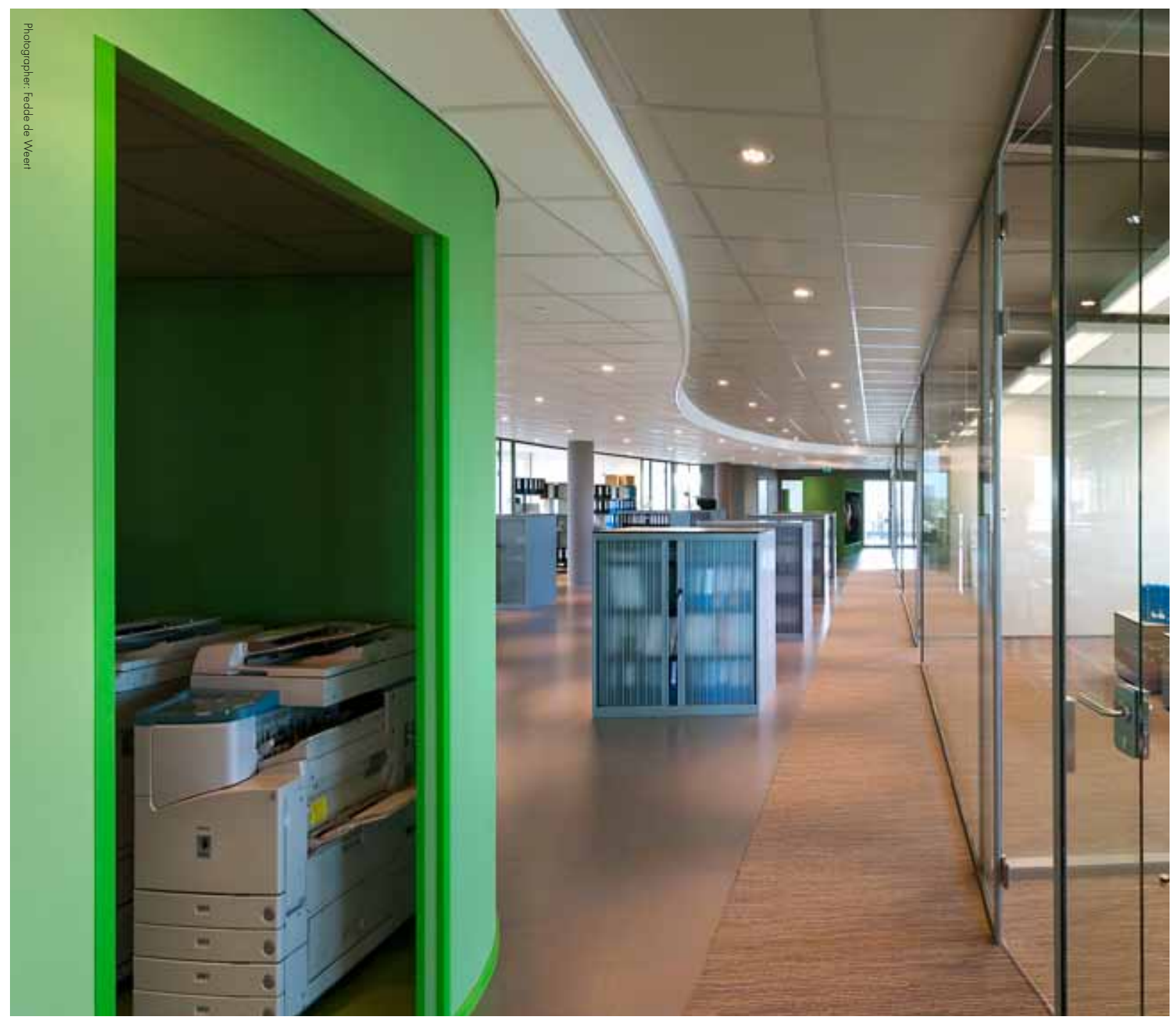




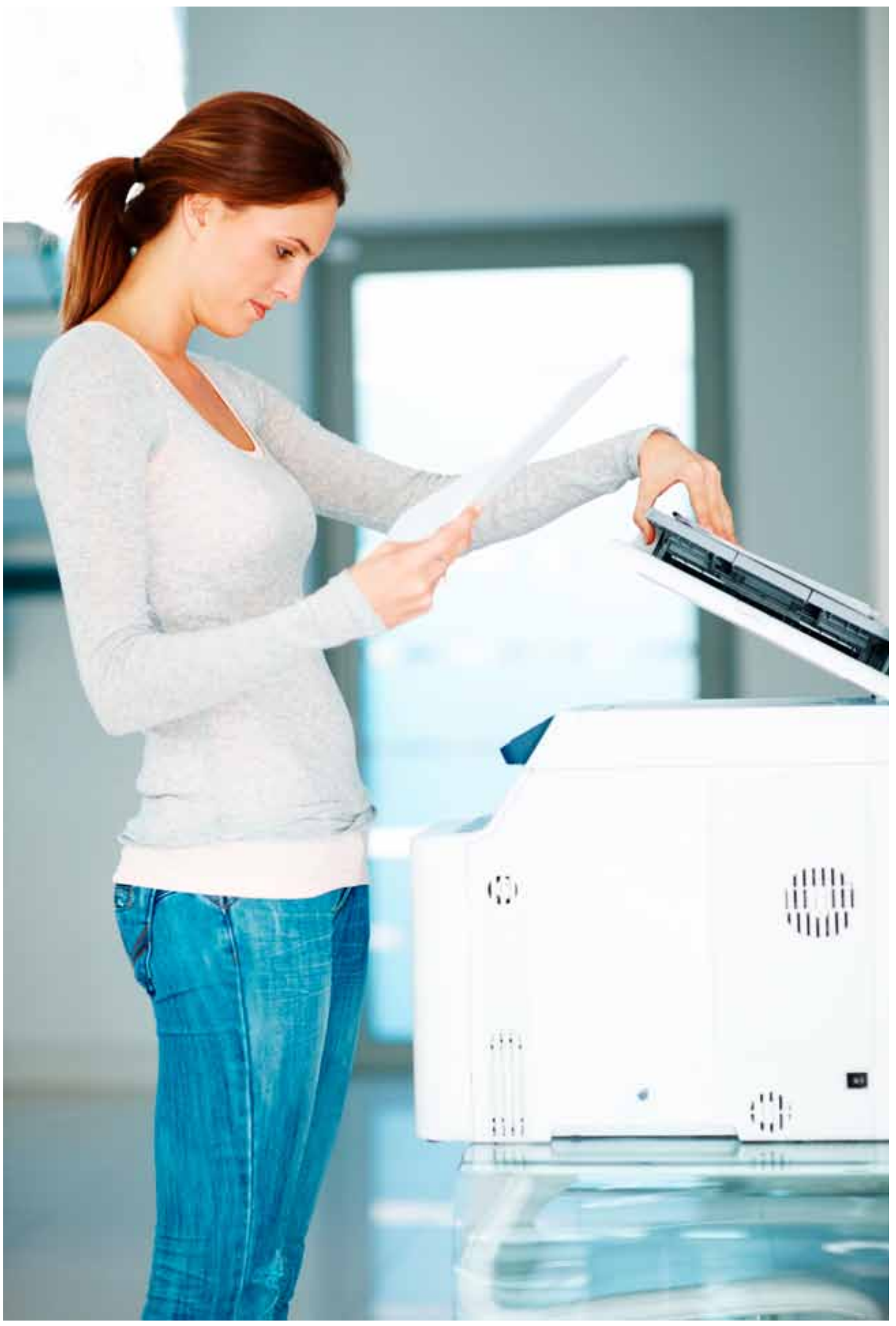


A meeting room plays a key role in interpersonal communication. The acoustic environment in the meeting room must be planned and designed according to the main activities to be performed there, to enhance efficiency and productivity.

Because a meeting room is frequently used for occasions where many people speak simultaneously, a low sound level should be prioritised. If the room is to be used for discussions and presentations, the main priority is that the speech should be heard clearly by everyone throughout the room. If the room is more than 12 metres long, sound-reflective surfaces should be positioned between the speaker and the listeners to prevent late sound reflections that impair speech perception. Wall absorbers should also be installed at ear height on the wall opposite the speaker. Sensitive subjects are often discussed in meeting rooms, so confidentiality requirements must be achieved.

\section{The room}

Most meeting rooms have hard, parallel walls. This can sometimes cause noise to bounce between the walls, a phenomenon known as flutter echo. This can be prevented by installing a wall absorber at ear height, or by inclining one of the walls so that the sound is conducted upwards to the acoustic ceiling. In light of this, when choosing fittings of this type, care must be taken to make sure they have the appropriate acoustic properties.

\section{Acoustic preferences}

To create a functional acoustic environment in the meeting room, one should aim to achieve a combination of good speech clarity, high speaker comfort and a low sound strength. The acoustic requirements become higher if electronic sound amplification and/or teleconference equipment is used. The walls' insulation value should be adapted to the level of confidentiality required in the meeting room. An insulation value of at least $44 \mathrm{~dB}$ is normally recommended.

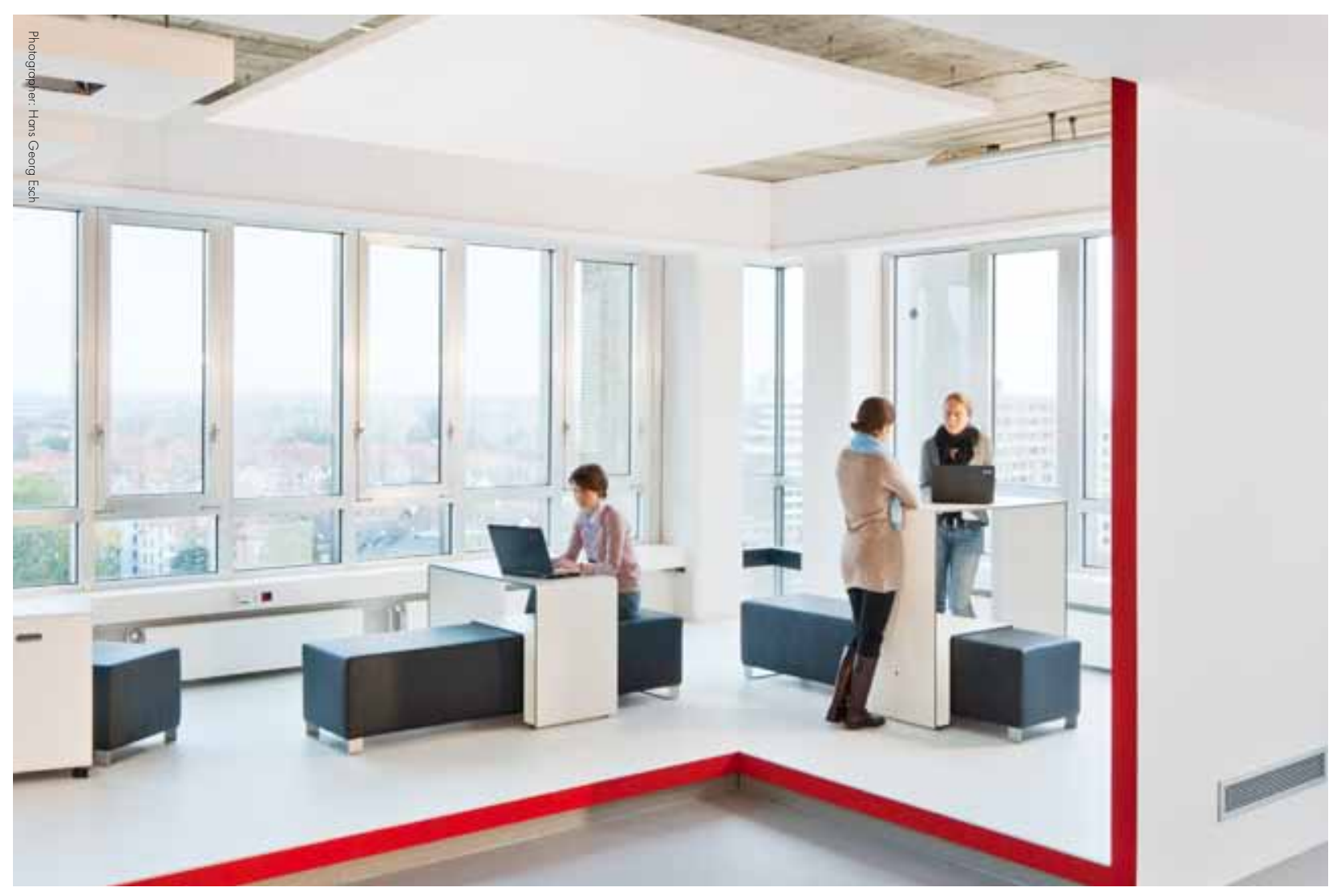



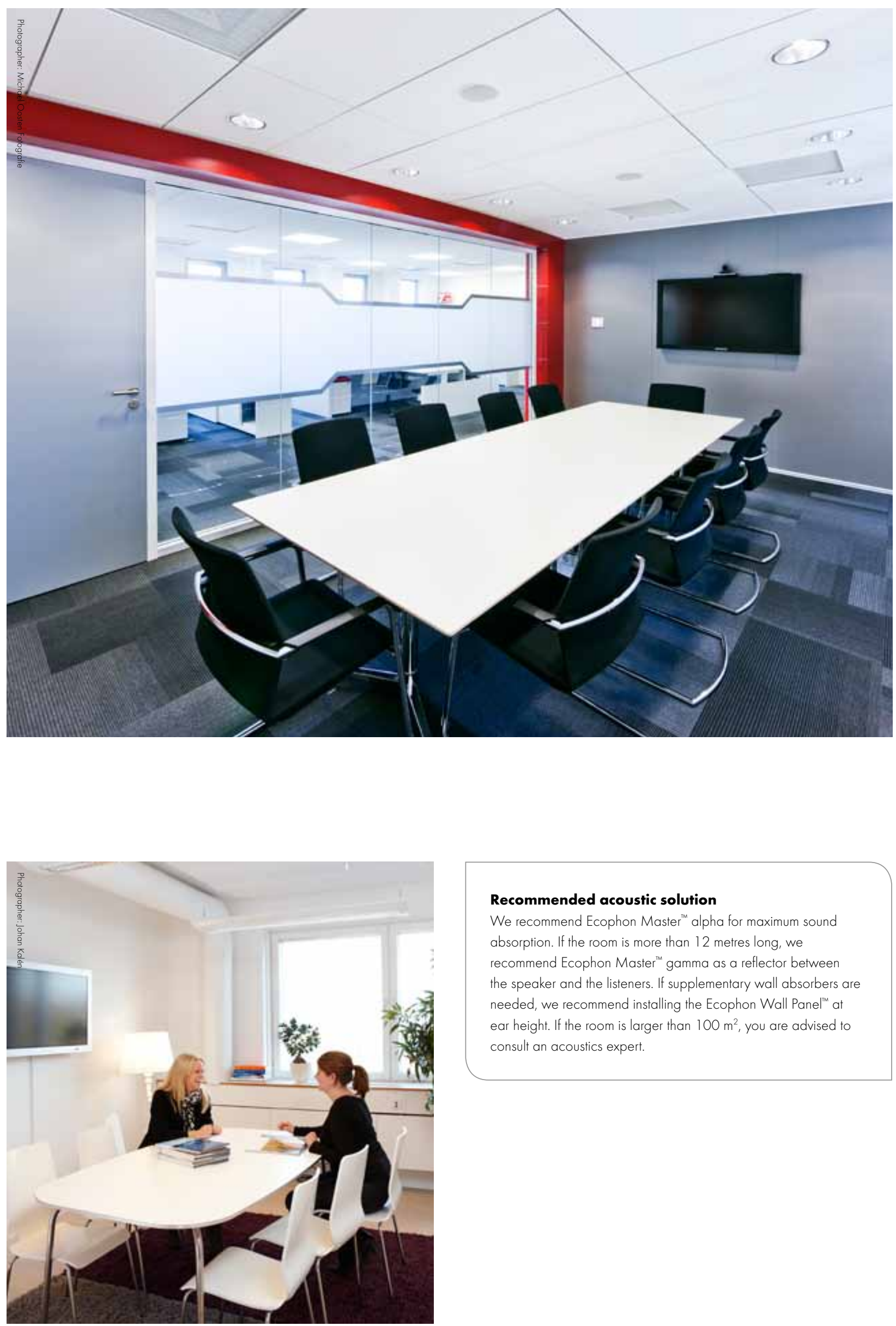

\section{Recommended acoustic solution}

We recommend Ecophon Master ${ }^{\text {rm }}$ alpha for maximum sound absorption. If the room is more than 12 metres long, we recommend Ecophon Master ${ }^{\text {rm }}$ gamma as a reflector between the speaker and the listeners. If supplementary wall absorbers are needed, we recommend installing the Ecophon Wall Pane $\left.\right|^{\text {Im }}$ at ear height. If the room is larger than $100 \mathrm{~m}^{2}$, you are advised to consult an acoustics expert. 


\section{System solutions for energy efficient buildings}

The modern society is moving towards more sustainable solutions in every aspect. When it comes to designing energy efficient buildings, architects can use the thermal mass of the exposed soffit for more efficient cooling of the rooms. There are both passive and thermally activated building systems, also referred to as TABS. Both systems help to create a suitable temperature in the building without the need to install further cooling systems.

\section{Sound reflections create problems}

TABS and similar systems present the potential for huge energy savings in buildings and provide a way to meet regulations for energy efficiency, but create a challenge when it comes to the sound environment. It is not possible to install a fully covering acoustic ceiling, and the exposed concrete necessary for cooling reflects sound, acting like a sound mirror. Without acoustic solutions, a high amount of sound reflections will be present in the room, creating an unfavourable working environment.

\section{Recommended acoustic solution}

In order to enhance the sound environment in TABS-buildings, free hanging units (Ecophon Solo ${ }^{\mathrm{TM}}$ ) or baffles (Ecophon Solo ${ }^{\mathrm{TM}}$ Baffle) can be used. In order to further compensate for the lack of a fully covered acoustic ceiling, introducing wall panels (Ecophon Wall Panel ${ }^{\mathrm{TM}}$ ) to the room is necessary to increase the total amount of sound absorption in the room, thus improving the sound environment. 


\section{Using design possibilities \\ to support wellbeing}

Ecophon's wide range of acoustic systems allows good acoustics to be combined with appealing visual design. Our ceiling absorbers are available in a variety of shapes, sizes, edges, surface finishes and colours. If you want to define the room still further, for example by creating a feeling of division, or if you want to experiment, we have a variety of free-hanging sound absorbers.
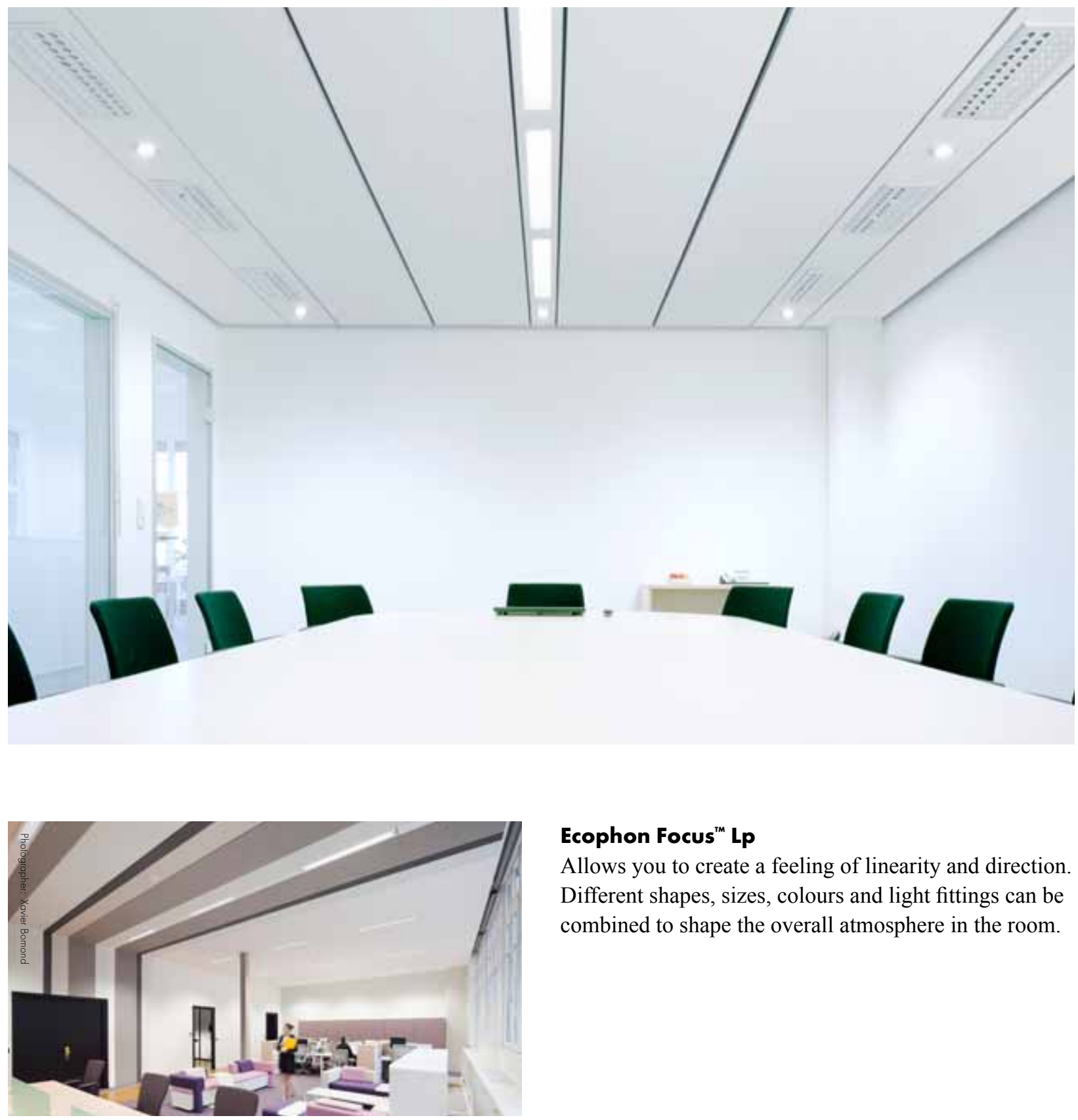

\section{Ecophon Focus ${ }^{\text {Tm }}$ Lp}

Allows you to create a feeling of linearity and direction. Different shapes, sizes, colours and light fittings can be combined to shape the overall atmosphere in the room. 


\section{Ecophon Solo ${ }^{\text {tm }}$}

This is a range of free-hanging sound absorbers in different shapes and colours that offer ample scope for tailoring the acoustic and visual environment. The acoustic ceiling can be supplemented with wall absorbers, which can also function as design elements. Absorbers are available in different colours and designs which can be combined to create an interesting space.

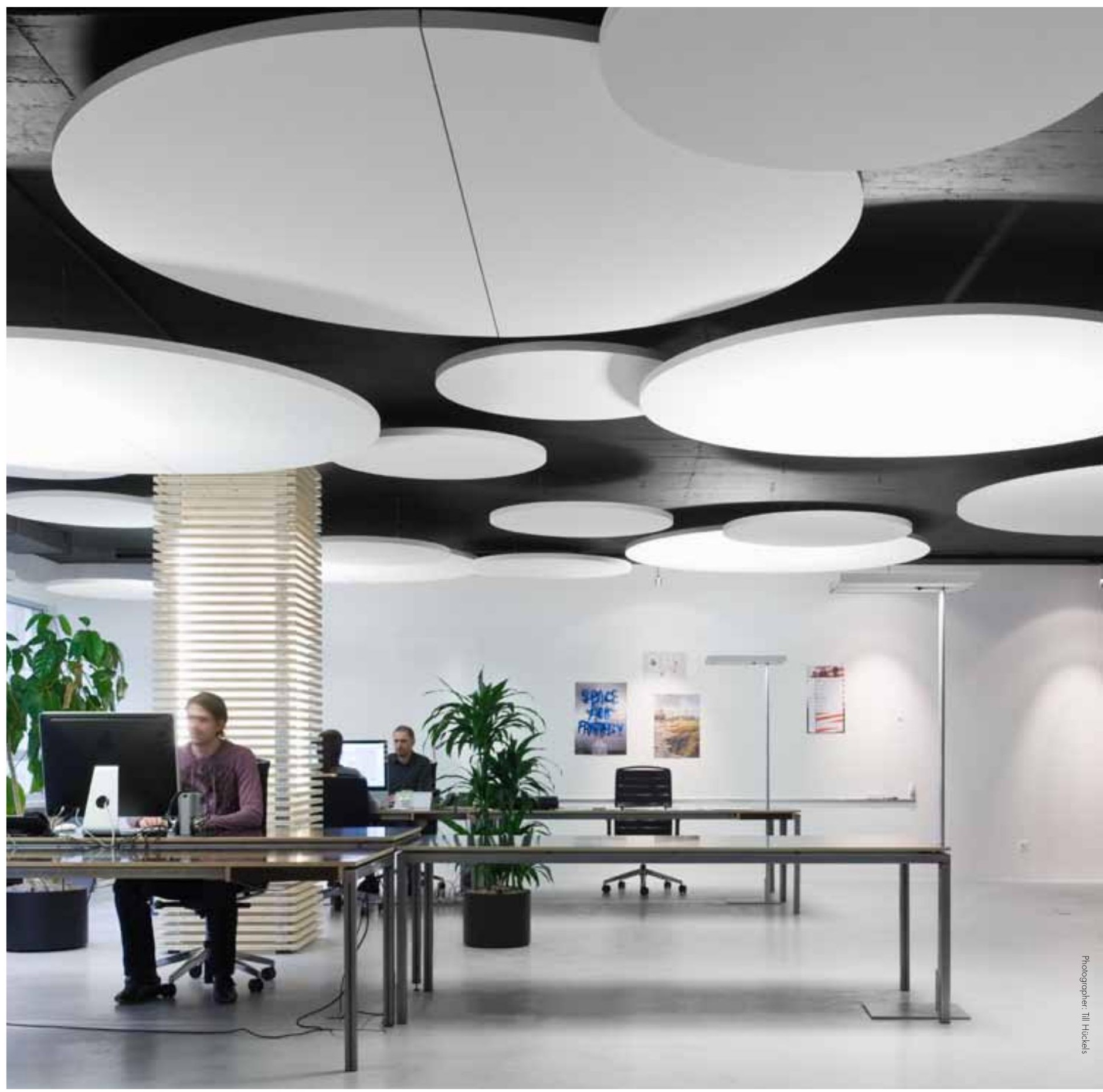





\section{Ecophon Wall Panel ${ }^{\mathrm{m}}$}

The range includes wall absorbers in a variety of combinations, available with different surface finishes, colours and profiles. Various graphic designs are available for creating distinctive interiors with unique patterns and motifs.
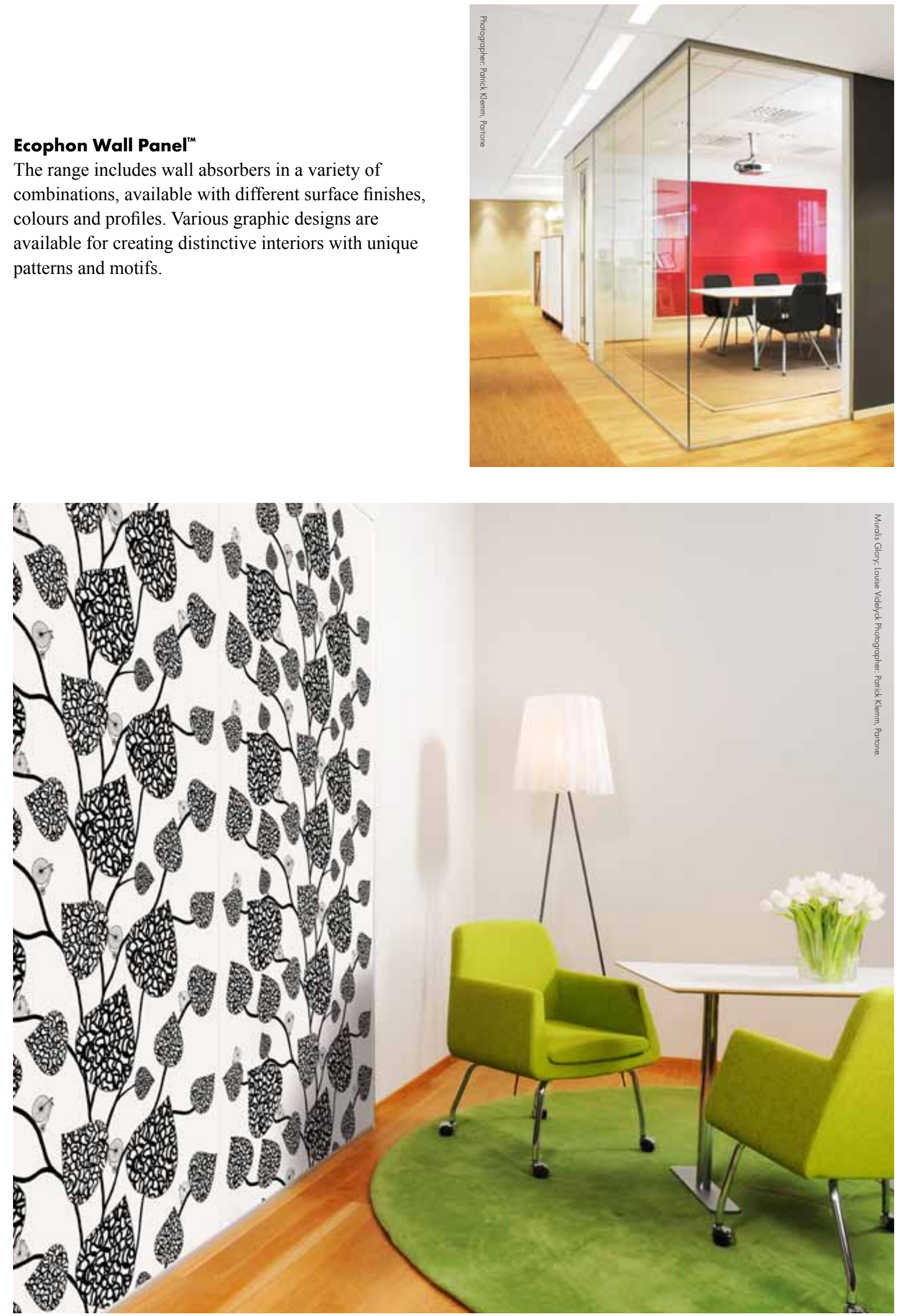


\section{are key aspects in choosing acoustic solutions}

\section{Free from dust and emissions}

The indoor environment impacts strongly on people's health and satisfaction in the workplace. Our acoustic systems are tested and assessed by many leading institutes. Ecophon acoustic products meet the strictest requirements under Danish Indeklima (Indoor Climate) and Finnish M1 standards, and are recommended by the Swedish Asthma and Allergy Association.
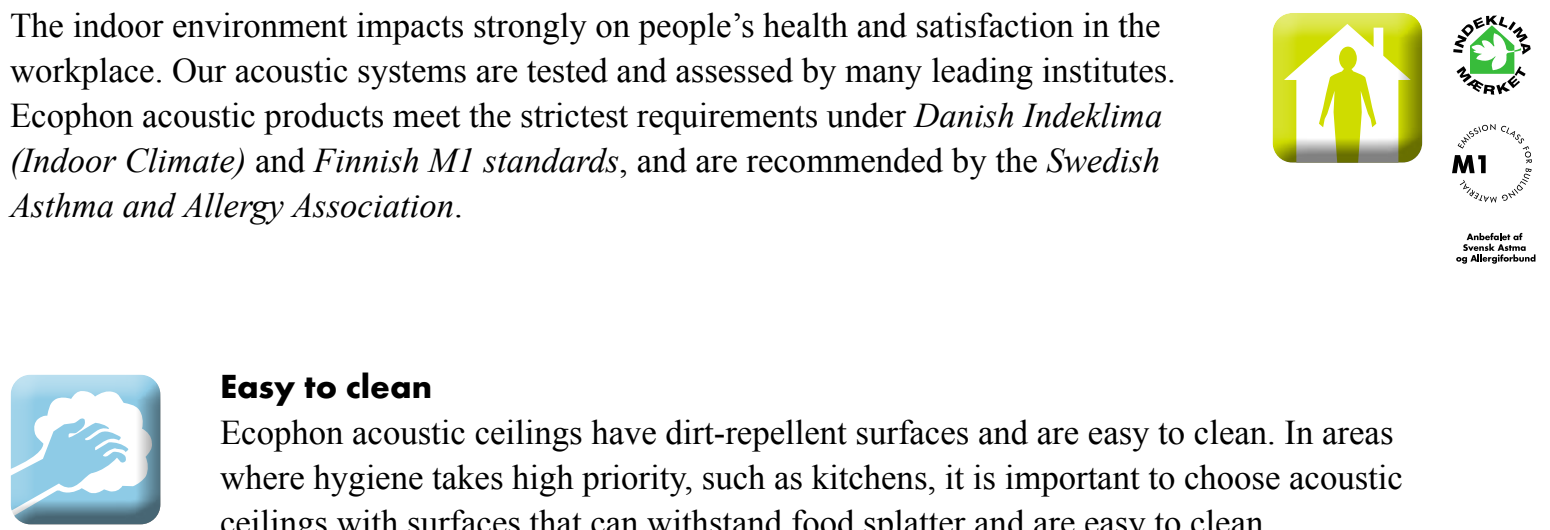

\section{Easy to clean}

Ecophon acoustic ceilings have dirt-repellent surfaces and are easy to clean. In areas where hygiene takes high priority, such as kitchens, it is important to choose acoustic ceilings with surfaces that can withstand food splatter and are easy to clean.

\section{High light efficiency}

Lighting is also a key factor in a working environment. Ecophon acoustic ceilings provide high and uniform light reflection, thus contributing to comfortable light diffusion and cost-effective lighting. Ecophon acoustic ceiling panels with Akutex ${ }^{\text {TM }}$ coating have a light reflection factor of $85 \%$ and a light diffusion factor of $99 \%$.
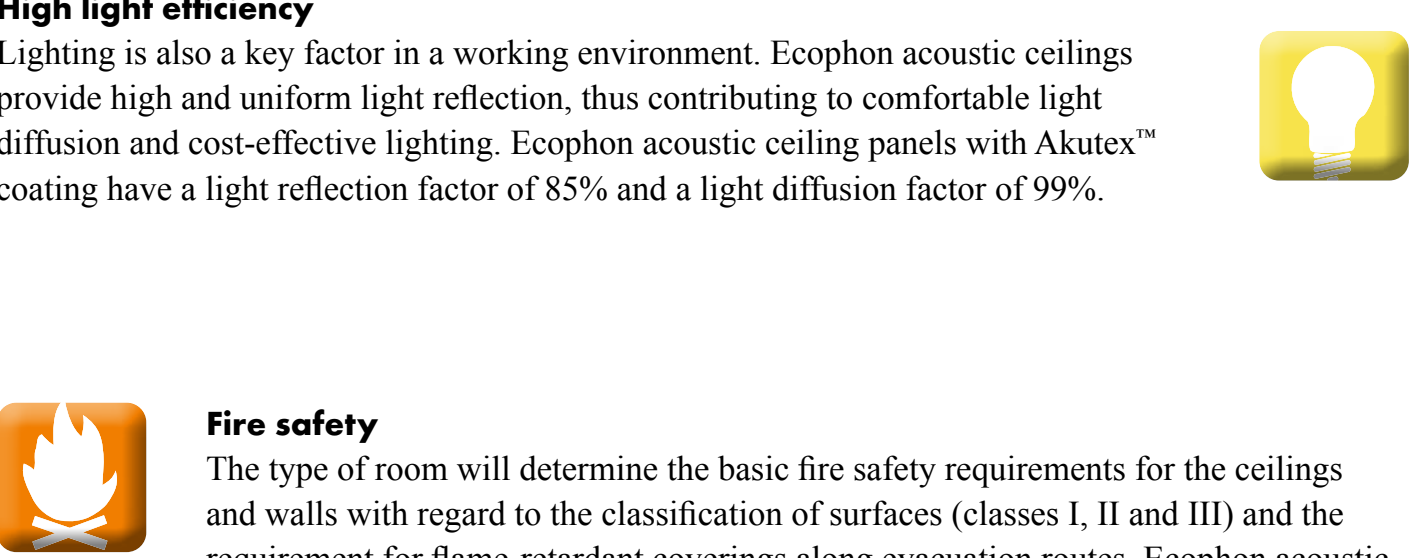

\section{Fire safety}

The type of room will determine the basic fire safety requirements for the ceilings and walls with regard to the classification of surfaces (classes I, II and III) and the requirement for flame-retardant coverings along evacuation routes. Ecophon acoustic systems meet all these requirements.

\section{Environment}

Our absorbers are made of glass wool, roughly $70 \%$ of which consists of recycled household glass. Waste materials from production are recycled into drainage pellets. The supporting structures are made of galvanised steel consisting of $50 \%$ recycled material, and are fully recycled after use. Ecophon also works to minimise
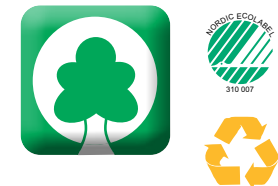
environmental impact by using environmentally friendly packaging and rational transportation. Most Ecophon products are marked with the Nordic Swan Ecolabel. 


\section{Choose a system \\ that matches the acoustic design}

When choosing an acoustic system, it is vital to make sure that the products' performance matches your acoustic requirements and preferences. At Ecophon, we work with four acoustic qualities to describe the acoustic requirements - sound strength, sound propagation, speech clarity and reverberation. Ecophon systems are designed to ensure the best possible performance for each of the qualities.

\section{Sound strength}

If a low sound strength is the main priority - choose absorbing products with the highest possible absorption factor $(\alpha)$.

\section{Sound propagation}

To ensure short sound propagation, choose absorbing products with high articulation class values $(A C)$, preferably $>180$. The higher the $\mathrm{AC}$ value, the shorter the sound propagation.

\section{Speech clarity}

If speech clarity is the main priority - contact Ecophon to choose the right combination of absorbers and reflectors.

\section{Reverberation}

If reverberation is the main priority - contact Ecophon to choose the right combination of absorbers and reflectors..

For open plan environments it is important to focus on the acoustic quality sound propagation, and thus products with high AC-values.

\section{Product performance}

Sound absorption class - sound absorbers are categorised in classes A-E. Class A has the highest sound absorbing capacity and class $E$ has the lowest, according to EN ISO 11654 .

Sound absorption factor - a measure of the extent to which the sound is absorbed, measured according to EN ISO 354

$\alpha=1$ means that all sound that reaches the absorber is absorbed.

$\alpha=0$ means that all the sound is reflected.

Articulation Class (AC) - is a measure for rating a ceiling's effectiveness in limiting sound propagation. The higher a product's AC value, the shorter the sound propagation. AC is measured according to ASTM E 111 1-07/E 11 10-06. 


\section{Ecophon product families \\ suitable for modern office environments}

\section{Ecophon Focus $^{\text {Tm }}$}

The Ecophon Focus range includes a series of products with different edge designs and installation options.

This allows it to be used in most applications regardless of installation and design.

- A modern colour range

- Contributes to an aesthetically pleasing and practical indoor environment

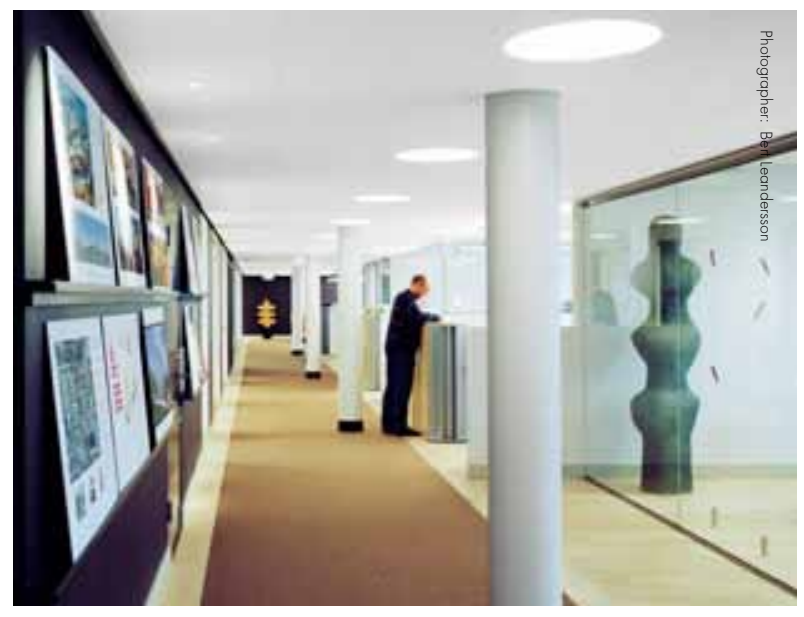

Specific Technical properties

\begin{tabular}{|c|c|c|c|}
\hline Product & Edge & Articulation Class* & $\begin{array}{l}\text { Sound absorption } \\
\text { coefficient }\left(\alpha_{w}\right)^{* *}\end{array}$ \\
\hline
\end{tabular}

Focus $^{\text {TM }}$ A Visible grid Easy demountable tiles
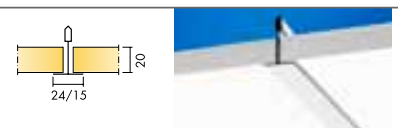

190

0,95

Focus $^{\text {TM }}$ B For direct fixing with glue
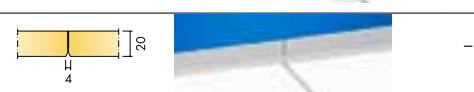

0,6(MH) (o.d.s $23 \mathrm{~mm}$ )

Focus $^{\text {TM }}$ Ds Concealed grid. Easily demountable tiles. Symmetric edge.

Focus $^{\text {TM }}$ Dg Unique edge design. Floating appearance. Easily demountable tiles.

Focus $^{\text {TM }}$ E Recessed visible grid. Easily demountable tiles.

\section{$\sum_{4}^{0}$}
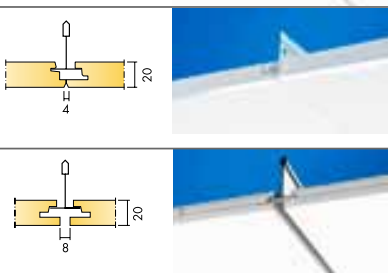

180

0,85

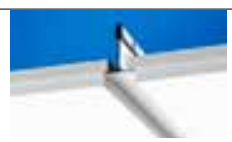

180

0,9

0,9

Focus $^{\text {TM }}$ Lp Semi-concealed grid system used for highlighting direction in a room

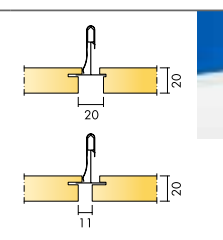

Focus $^{\mathrm{TM}} \mathbf{F}$ For direct fixing with screws.
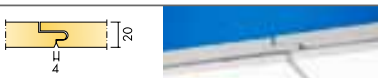

$0,6(\mathrm{MH})$ (o.d.s $20 \mathrm{~mm}$ ) 

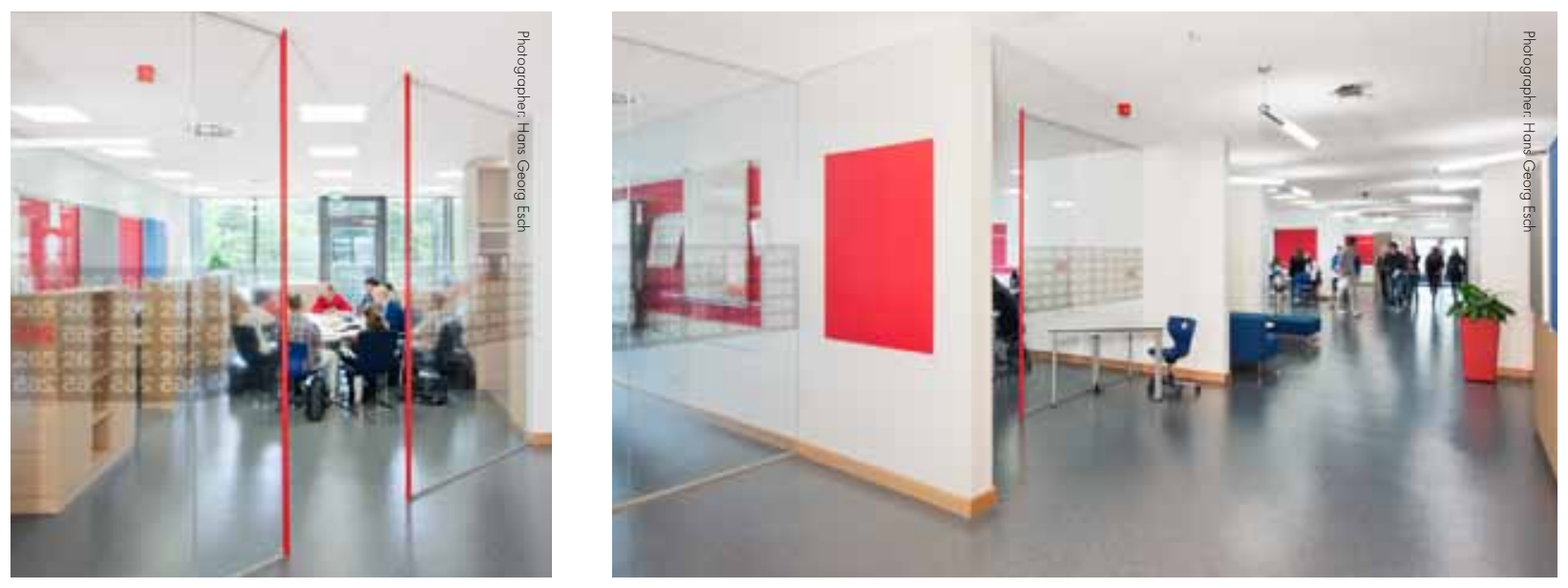

\section{Ecophon Master $^{\text {Tm }}$}

Ecophon Master is in a class of its own when it comes to promoting speech clarity. It has excellent sound absorption for frequencies above $250 \mathrm{~Hz}$ and also provides high absorption for low frequencies. Therefore, Master is particularly well suited for rooms where maximum absorption throughout the frequency range is desirable, such as classrooms and open-plan offices. It is also ideal in areas where there is lowfrequency disturbance from ventilation systems or external sources such as traffic noise.
- Product system for creating the optimum acoustic environment in teaching premises.

- Also useful in large meeting rooms.

- Several different designs give a choice of aesthetic and practical possibilities.

\section{Specific Technical properties}

\begin{tabular}{|c|c|c|c|}
\hline Product & Edge & Articulation Class* & $\begin{array}{l}\text { Sound absorption } \\
\text { coefficient }\left(\alpha_{w}\right)^{* *}\end{array}$ \\
\hline $\begin{array}{l}\text { Master }{ }^{\text {TM }} \text { A Visible grid. Easily demountable } \\
\text { tiles. }\end{array}$ & & 200 (alpha) & 1 (alpha) \\
\hline Master $^{\text {TM }}$ B For direct fixing with glue. & & - & 1 (o.d.s. $40 \mathrm{~mm}$, alpha) \\
\hline Master $^{\text {TM }}$ Ds Concealed grid. Easily & & 200 (alpha) & 0,9 (alpha) \\
\hline demountable tiles. & & & \\
\hline 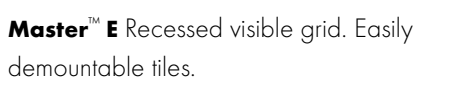 & & 190 (alpha) & 0,95 (alpha) \\
\hline $\mathbf{M a s t e r}^{\text {TwM }} \mathbf{F}$ For direct fixing with screws. & 7 & - & 1 (o.d.s. 40 m, alpha) \\
\hline
\end{tabular}



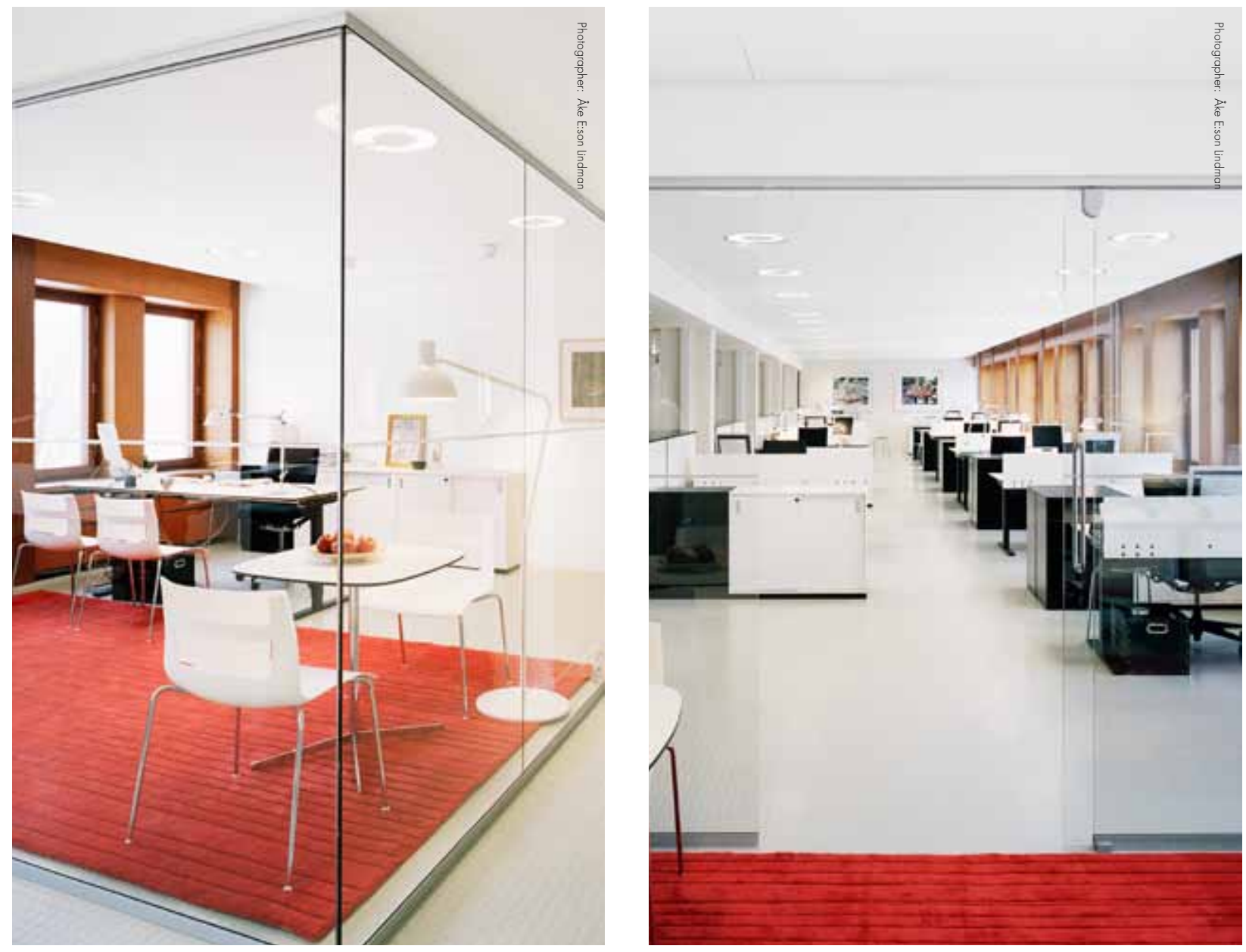

\section{Ecophon Combison $^{\text {TM }}$}

In modern office buildings it is often desirable to use partition walls to create versatile spaces that meet tenants' needs. To provide privacy between spaces it is important that sound cannot travel through the ceiling over walls. Ecophon Combison products fill this need.

- Various systems for acoustic insulation combined with good sound absorption

- Enables flexible room division

- Easy access to space above ceiling

Specific Technical properties

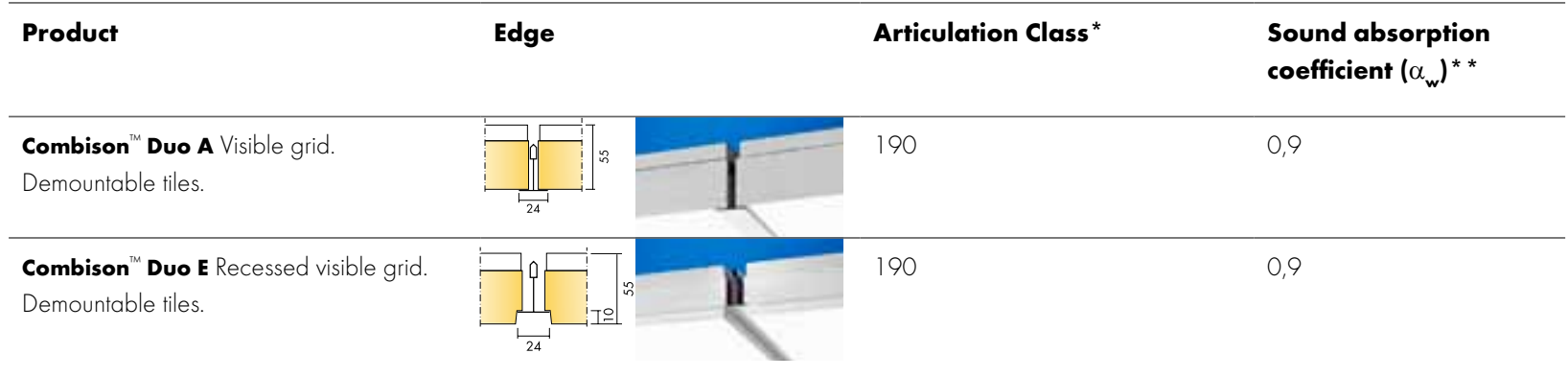

*) AC(1.5) according to ASTM E 111 and E 1110 


\section{Ecophon Solo ${ }^{\text {TM }}$}

Ecophon Solo is a family of free-hanging sound absorbers available in different shapes and colours. In Solo Regular you find 10 shapes inspired by geometry. With Solo Freedom we give you the possibility to create your own shape. Solo has three different suspension systems to choose from, depending on the expression you want to create in the ceiling. Solo gives you the possibility to create eye catching installations that improve the sound environment in many different types of premises, for example offices, cultural buildings, entrance halls and restaurants. Solo can also be used in buildings with TABS (thermally activated building systems) to create a good sound environment.

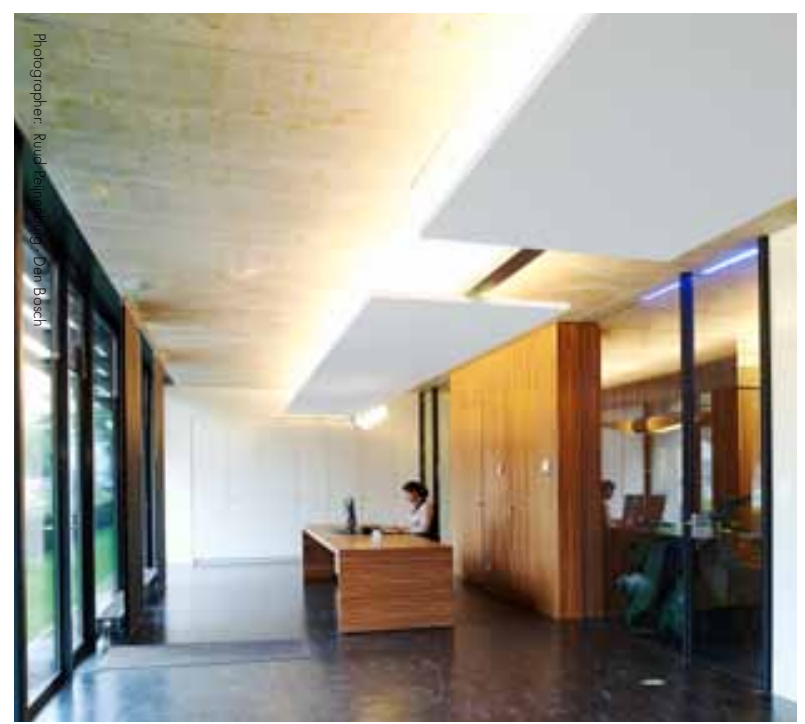

\section{Specific Technical properties}

\section{Product}

Product

Focus' Wing Wing-shaped elements for free hanging ceilings.

\section{Edge}

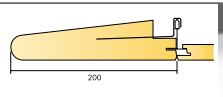

\section{Product info}

Adding free hanging units to an existing acoustic ceiling is an efficient way to further reduce sound propagation

\begin{tabular}{|c|c|}
\hline $\begin{array}{l}\text { Edge }{ }^{\text {TM }} \mathbf{5 0 0} \text { Slight vertical sloped moulding } \\
\text { for free hanging units. }\end{array}$ & $\begin{array}{l}\text { Adding free hanging units to an existing acoustic ceiling is an } \\
\text { efficient way to further reduce sound propagation }\end{array}$ \\
\hline $\begin{array}{l}\text { Solo }{ }^{\text {Tm }} \text { A family of free hanging units with a } \\
\text { clean appearance and an easy installation. } \\
\text { Discreet, adjustable wire hangers with } \\
\text { novisible profiles. }\end{array}$ & $\begin{array}{l}\text { Adding free hanging units to an existing acoustic ceiling is an } \\
\text { efficient way to further reduce sound propagation }\end{array}$ \\
\hline Solo ${ }^{\text {TM }}$ Baffle Suspended with Baffle profile. & $\begin{array}{l}\text { Adding free hanging units to an existing acoustic ceiling is an } \\
\text { efficient way to further reduce sound propagation }\end{array}$ \\
\hline
\end{tabular}

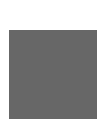

Ecophon Solo's" Square - Standard size: $1200 \times 1200 \mathrm{~mm}$

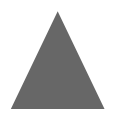

Ecophon Solo Triangle - Standard height: $1039 \mathrm{~mm}$ Standard leg lenght: $1200 \mathrm{~mm}$

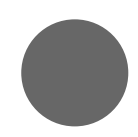

$$
\begin{aligned}
& \text { Ecophon Solo Circle - } \\
& \text { Standard sizes } \varnothing \text { : }
\end{aligned}
$$
$800 \mathrm{~mm} \varnothing: 1200 \mathrm{~mm}$

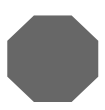

Ecophon Solo"

Octagon - Standard dimensions: $1200 \times 1200 \mathrm{~mm}$

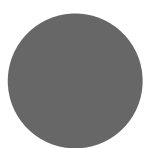

Ecophon Solo Circle XL - Standard $X L$ size $\varnothing: 1600 \mathrm{~mm}$

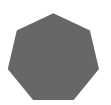

Ecophon Solo Heptagon Standard dimensions: $1168 \times 1198$ mm
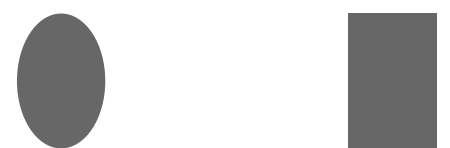

Ecophon Solo Ellipse - Standard size: $2400 \times 1000 \mathrm{~mm}$

Ecophon Solo Rectangle - Standard size $2400 \times 1200 \mathrm{~mm}$
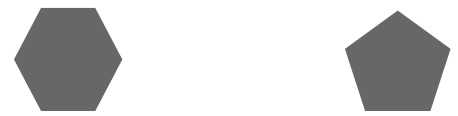

Ecophon Solo Hexagon Standard dimensions $1040 \times 1200 \mathrm{~mm}$
Ecophon Solo Pentagon Standard dimensions $1139 \times 1198$ mm 


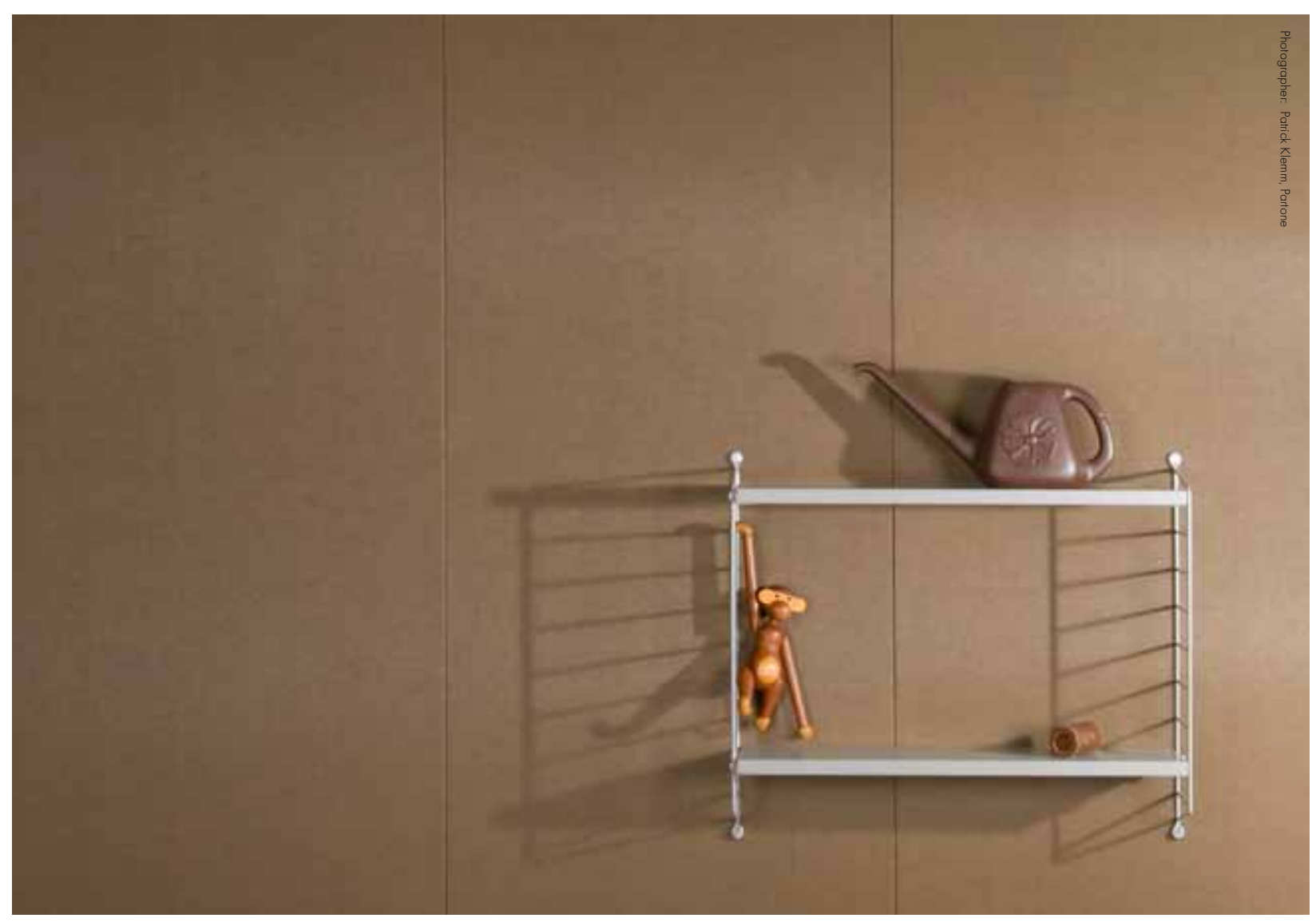

\section{Ecophon Wall Panel ${ }^{\text {mm }}$}

In some premises it is only possible to use sound absorbents on the walls, not the ceiling, or it may be necessary to supplement an acoustic ceiling with additional sound absorption. Ecophon Wall Panels include products for a range of applications, such as schools, offices and sports halls.
- Choice of different surfaces to suit the application

- Modern colour range

- Modern profile system that is easy to install

\section{Specific Technical properties}

\begin{tabular}{|c|c|c|c|}
\hline Product & Edge & Articulation Class * & $\begin{array}{l}\text { Sound absorption } \\
\text { coefficient }\left(\alpha_{w}\right)^{* *}\end{array}$ \\
\hline $\begin{array}{l}\text { Wall Panel }^{\text {TM }} \text { A A Visible profiles. Panel } \\
\text { width } 1200 \mathrm{~mm} \text {. }\end{array}$ & $\underbrace{}_{24} \quad 0$ & 230 & 0,95 \\
\hline $\begin{array}{l}\text { Wall Panel }{ }^{\text {TM }} \text { C Concealed vertical profiles. } \\
\text { Panel width } 600 \mathrm{~mm} \text {. }\end{array}$ & 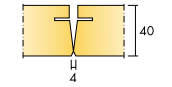 & 240 & 1 \\
\hline
\end{tabular}

*) AC(1.5) according to ASTM E 1376 and E 1110 


\section{Recommendations}

\section{for sound design of modern offices}

To create a functional, comfortable acoustic environment, the following aspects should be taken into account:

- Information - let people know, and make sure they understand the thoughts and ideas behind the new layout.

- Positioning of workstations - arrange workstations so that people who need to communicate sit close together. Create silent rooms where people can achieve concentration-

intensive work or talk without disturbing others.

- Room design - choose ceilings, walls and flooring that duplicate the outdoor environment and promote good acoustics. Install sound absorbers on ceilings and walls, and

supplement them with sound absorbing screens to reduce sound propagation and noise levels.

- Choice of equipment - choose silent equipment to minimise noise from ventilation systems and office machinery, and locate printers in acoustically insulated rooms wherever

possible.

- Furnishing - choose furniture that improves sound absorption and position it in a way that optimises the acoustic environment.

- Behaviour - inform people how to behave in an open plan office environment to avoid disturbing their colleagues.

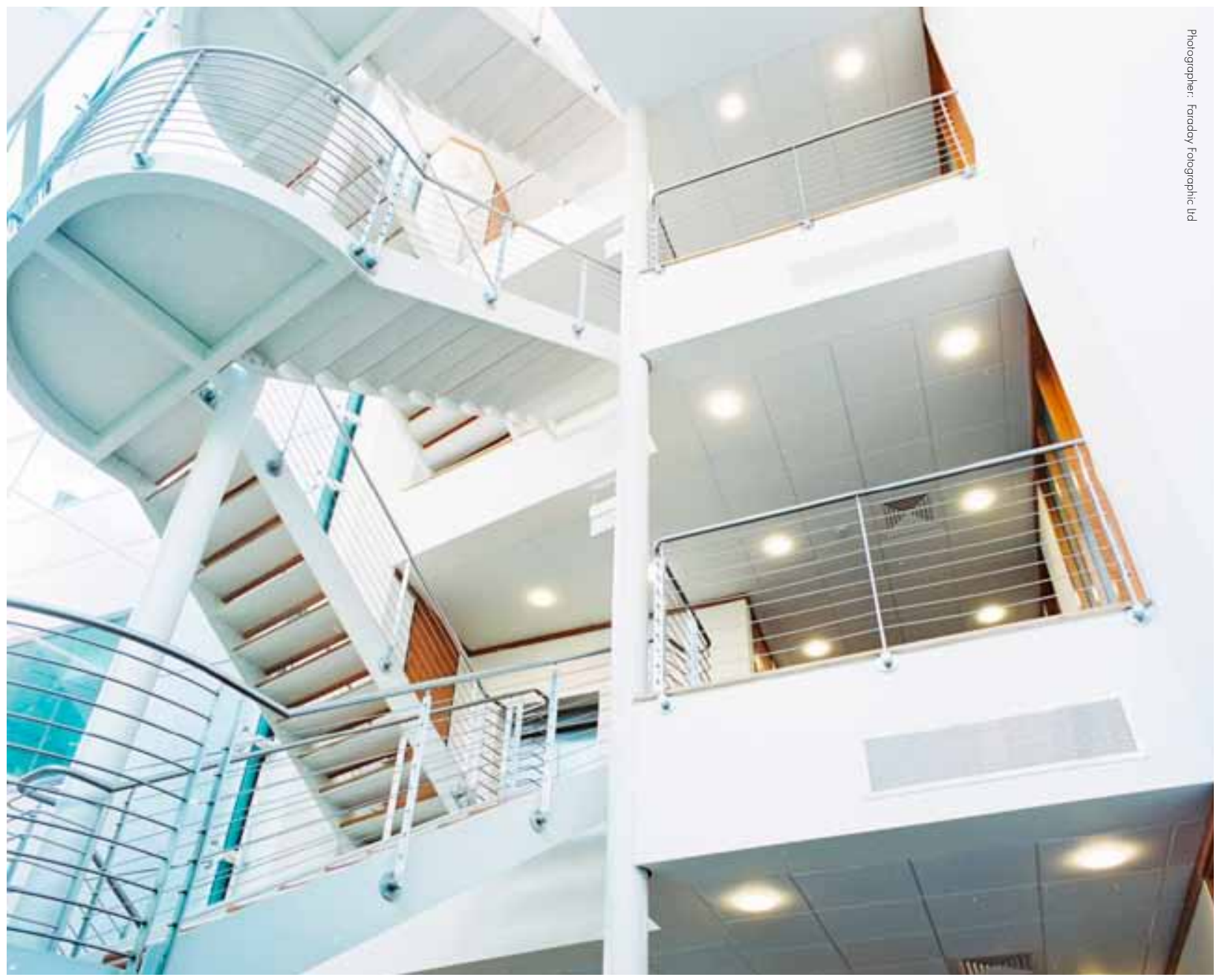




\section{Three steps to ensure a good sound environment e.g. At a helpdesk office in Sweden}

A helpdesk in an open plan office can be a very challenging acoustic scenario. In a study called "Acoustic design of open-plan offices" performed by the Nordic Innovation Centre*, the following improvements in the assessment of the sound environment were achieved by performing acoustic intervention in 3 steps, using Ecophon products and recommendations.

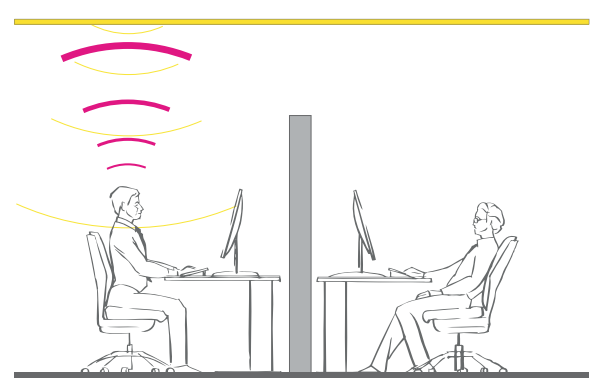

Step 1 - Make sure there is enough sound absorption in the room.

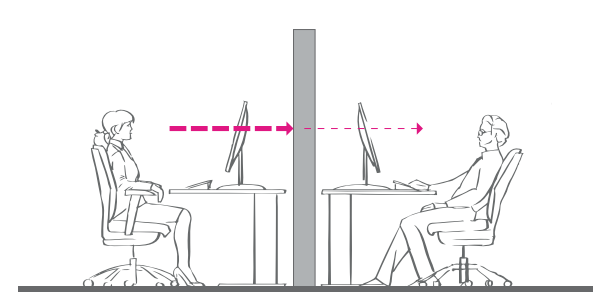

Step 2 - Use sound absorbing and insulating screens to minimize disturbance between

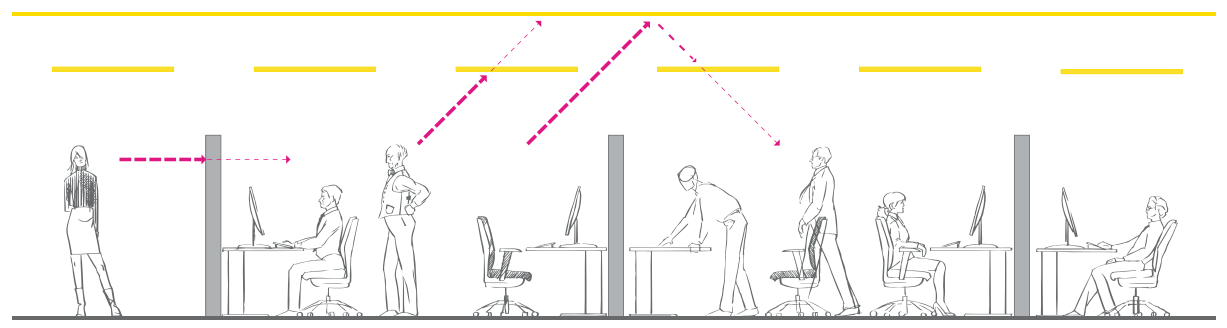

Step 3 - Use free hanging units over workspaces to further support the sound environment.

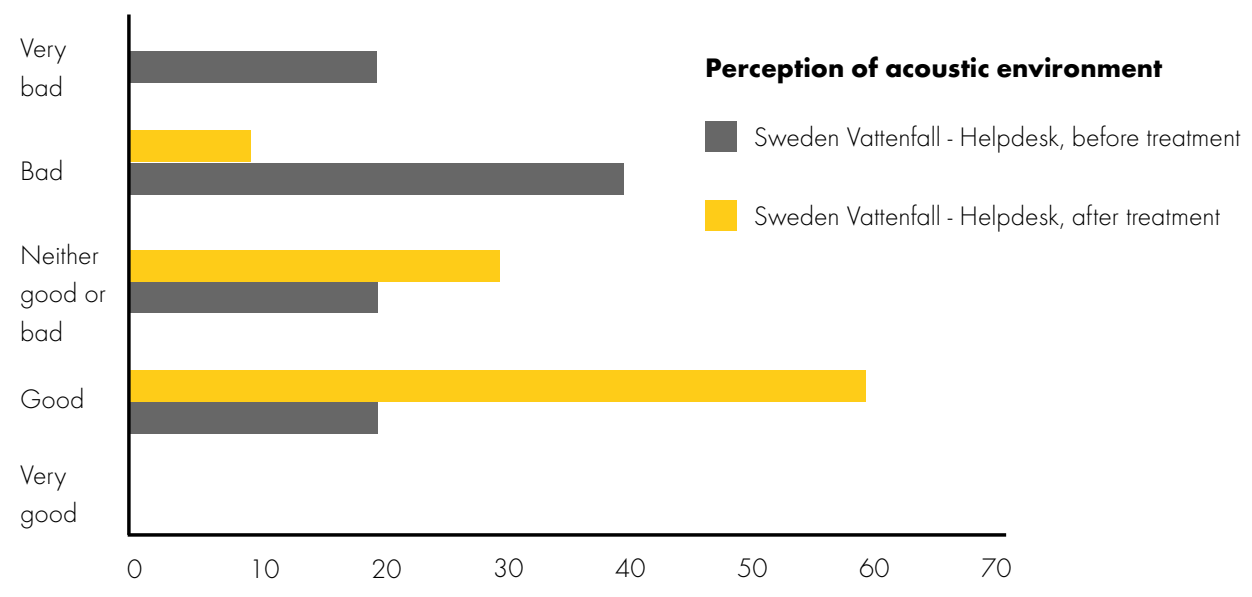




\section{Our expertise}

\section{at your disposal}

We help you to create acoustic comfort in the office environment. The key to success lies in good planning during the early stages. Our concept developers can assist you with the following needs:

- Identifying what demands should be placed on the acoustic environment, based on the room's design, the type of activities to be performed, and individual acoustic preferences

- Developing room acoustic specifications and sound policies

- Defining acoustic terminology and explaining office acoustic standards

- Developing acoustic solutions that meet your general needs

Our concept developers can also provide training, seminars and lectures on sound, hearing, and the latest research findings regarding room acoustics.

If you have any questions about our products or system solutions, please contact your Area Sales Manager, or our technical support. For more information on acoustics, systems and products on our website, visit www.ecophon.co.uk.

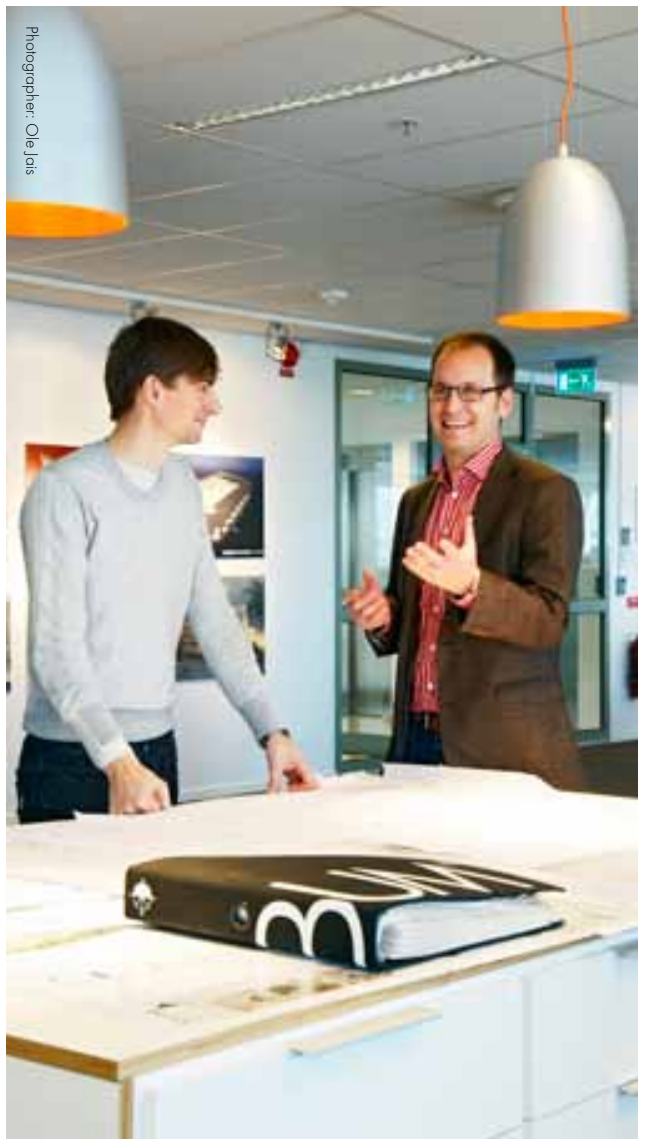

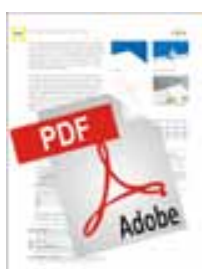

Print our product information online.

Automatically updated and therefore always up-to-date, you'll

find the PDF icon on all product

pages. www.ecophon.co.uk

\section{Contact details}

Switchboard +44 1256850977

www.ecophon.co.uk/Contact/ 


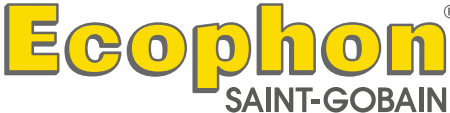

A SOUND EFFECT ON PEOPLE

Ecophon dates back to 1958, when the first sound absorbers from glass wool were produced in Sweden to improve the acoustic working environment. Today the company is a global supplier of acoustic systems that contribute to good room acoustics and a healthy indoor environment with the focus on offices, education, health care and industrial manufacturing premises. Ecophon is part of the Saint-Gobain Group and has sales units and distributors in many countries.

Ecophon's efforts are guided by a vision of earning global leadership in acoustic ceiling and wall absorber systems by providing superior end user value. Ecophon maintains an ongoing dialogue with government agencies, working environment organisations and research institutes, and is involved in formulating national standards in the field of room acoustics where Ecophon contributes to a better working environment wherever people work and communicate.

www.ecophon.co.uk

$\operatorname{mim}_{\text {SAINT-GOBAIN }}$ 